\title{
FGFR a promising druggable target in cancer: Molecular biology and new drugs
}

\author{
Rut Porta $^{\mathrm{a}, 1}$, Roberto Borea ${ }^{\mathrm{b}, 1}$, Andreia Coelho ${ }^{\mathrm{b}, 1}$, Shahanavaj Khan ${ }^{\mathrm{c}}$, António Araújo ${ }^{\mathrm{d}}$, \\ Pablo Reclusa ${ }^{\mathrm{b}}$, Tindara Franchina ${ }^{\mathrm{e}}$, Nele Van Der Steen ${ }^{\mathrm{f}}$, Peter Van Dam ${ }^{\mathrm{b}}$, Jose Ferri ${ }^{\mathrm{b}}$, \\ Rafael Sirera $^{\mathrm{b}}$, Aung Naing ${ }^{\mathrm{g}}$, David Hong ${ }^{\mathrm{g}}$, Christian Rolfo ${ }^{\mathrm{b}, *}$

\footnotetext{
${ }^{a}$ Department of Medical Oncology, Catalan Institute of Oncology (ICO), Girona, Spain; Girona Biomedical Research Institute (IDIBGi), Girona, Spain; Department of Medical Sciences, School of Medicine, University of Girona, Girona, Spain

${ }^{b}$ Phase I-Early Clinical Trials Unit, Oncology Department, Antwerp University Hospital (UZA) and Center for Oncological Research (CORE) Antwerp University, Edegem, Antwerp, Belgium²

' Nanomedicine and Biotechnology Research Unit, Department of Pharmaceutics, College of Pharmacy, King Saud University, Riyadh, Saudi Arabia

d Department of Medical Oncology, Centro Hospitalar do Porto, Porto, Portugal

${ }^{\mathrm{e}}$ Medical Oncology Unit A.O. Papardo \& Department of Human Pathology, University of Messina, Messina, Italy

${ }^{f}$ Center for Oncological Research (CORE), University of Antwerp, Wilrijk, Antwerp, Belgium; Department of Pathology, Antwerp University Hospital, Edegem, Antwerp, Belgium
} \\ g Department of Investigational Cancer Therapeutics, MD Anderson Cancer Center, Houston, TX, USA
}

\section{Contents}

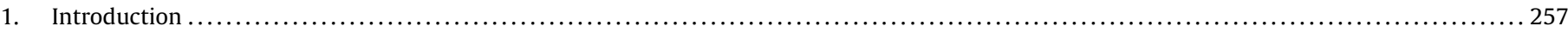

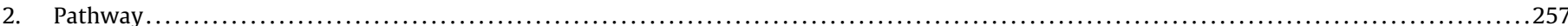

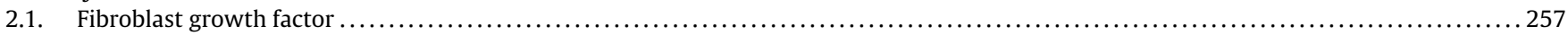

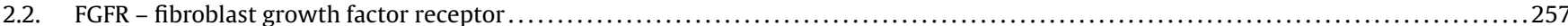

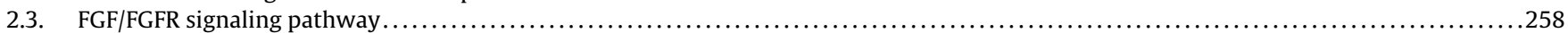

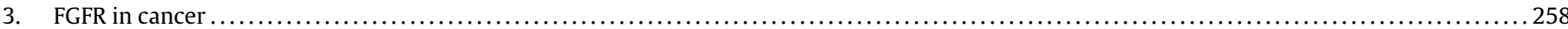

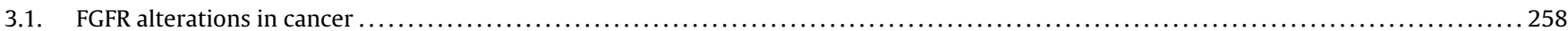

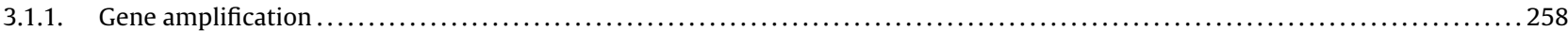

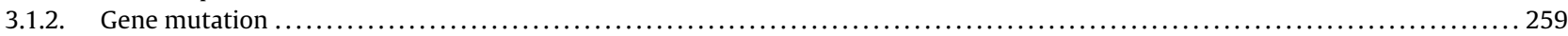

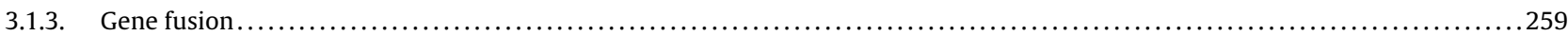

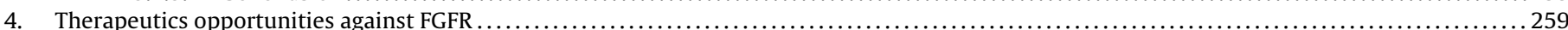

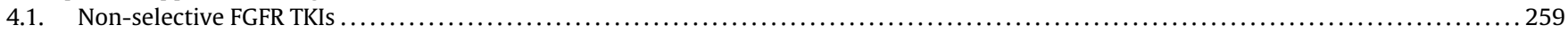

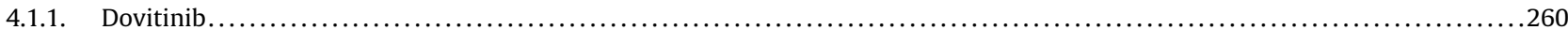

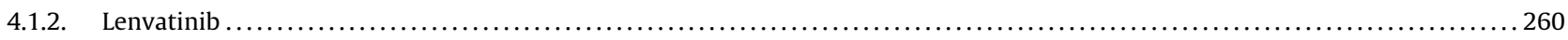

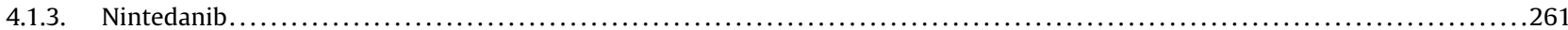

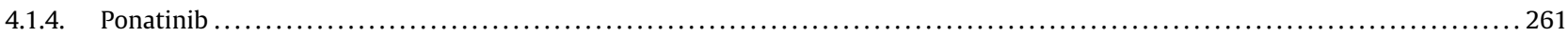

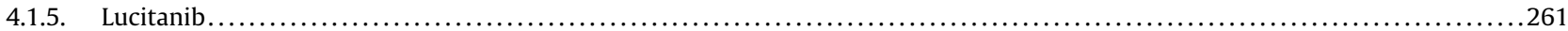

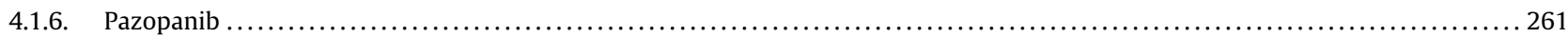

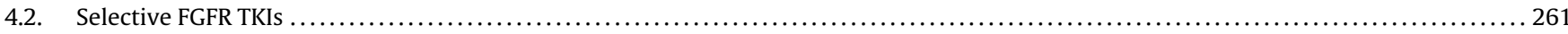

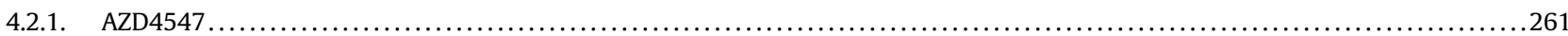

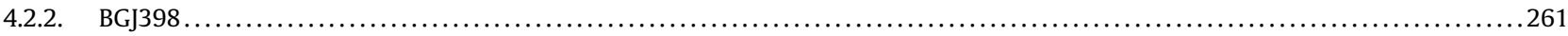

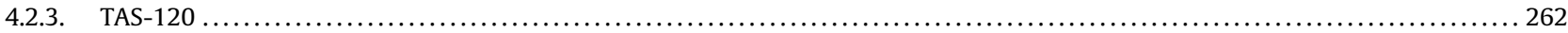

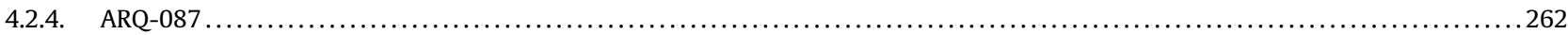

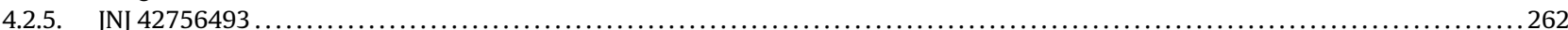

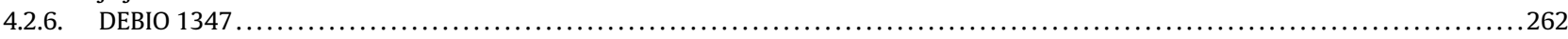

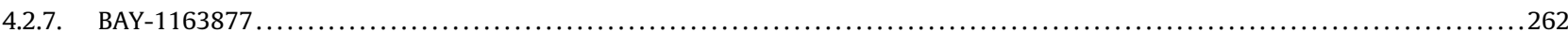

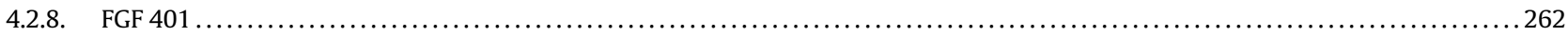

\footnotetext{
* Corresponding author at: Head of Phase I - Early Clinical Trials Unit, Director of Clinical Trial Management Program, Oncology Department, University Hospital Antwerp, UZA, Wilrijkstraat 10, 2650 Edegem, Belgium.

E-mail address: christian.rolfo@uza.be (C. Rolfo).

1 These authors contributed equally for this manuscript.

2 http://www.uza.be.
} 


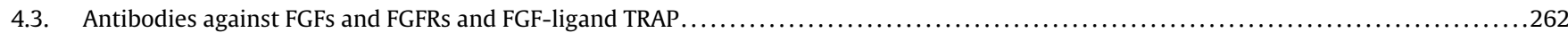

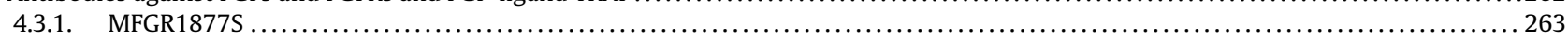

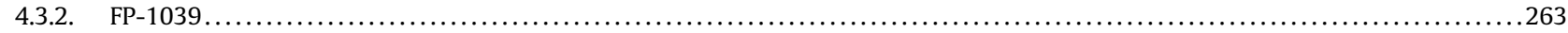

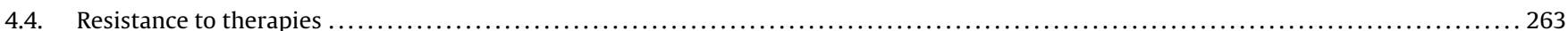

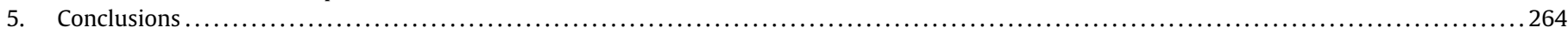

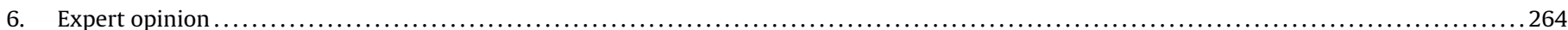

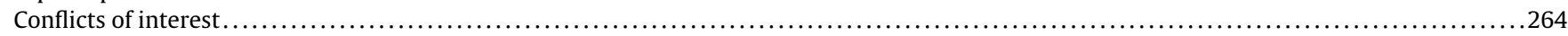

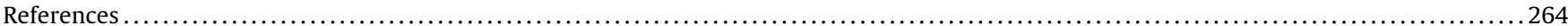

\section{A R T I C L E I N F O}

\section{Article history:}

Received 8 August 2016

Received in revised form 8 February 2017

Accepted 15 February 2017

\section{Keywords:}

Cancer

FGF

FGFR

FGFR inhibitors

\begin{abstract}
A B S T R A C T
Introduction: The Fibroblast Growth Factor Receptor (FGFR) family consists of Tyrosine Kinase Receptors (TKR) involved in several biological functions. Recently, alterations of FGFR have been reported to be important for progression and development of several cancers. In this setting, different studies are trying to evaluate the efficacy of different therapies targeting FGFR.

Areas Covered: This review summarizes the current status of treatments targeting FGFR, focusing on the trials that are evaluating the FGFR profile as inclusion criteria: Multi-Target, Pan-FGFR Inhibitors and anti-FGF (Fibroblast Growth Factor)/FGFR Monoclonal Antibodies.

Expert opinion: Most of the TKR share intracellular signaling pathways; therefore, cancer cells tend to overcome the inhibition of one tyrosine kinase receptor by activating another. The future of TKI (Tyrosine Kinase Inhibitor) therapy will potentially come from multi-targeted TKIs that target different TKR simultaneously. It is crucial to understand the interaction of the FGF-FGFR axis with other known driver TKRs. Based on this, it is possible to develop therapeutic strategies targeting multiple connected TKRs at once. One correct step in this direction is the reassessment of multi target inhibitors considering the FGFR status of the tumor. Another opportunity arises from assessing the use of FGFR TKI on patients harboring FGFR alterations.
\end{abstract}

(C) 2017 Elsevier B.V. All rights reserved.

\section{Introduction}

Our knowledge of the molecular alterations that drive cancer progression and response to treatment has driven the development of novel target therapies. The initial FGF was reported from fibroblasts as a mitogen more than four decades ago (Gospodarowicz, 1974). The fibroblast growth factor-receptor axis (FGF-FGFR) is involved in signal transduction pathways that regulate cell proliferation, differentiation, embryonic development, migration, survival, angiogenesis and organogenesis (Beenken and Mohammadi, 2009; Ornitz and Itoh, 2015). Over the last years several mutations and alterations in FGF-FGFR have been reported in cancer (Brooks et al., 2012). Therefore it has the potential to become a new target for cancer therapy development (Ornitz and Itoh, 2015). Moreover, specific alterations of FGFR are more frequent in certain types of tumors, thus making FGFR a suitable biomarker. Several TKIs have been evolved in order to inhibit FGFR and VEGFR domains, which share similar structures. According to this, we hypothesize that a dual inhibition of both receptors is a potential beneficial combination. However, many of these multi-TKIs are less capable of achieving an efficient FGFR inhibition and also increase side effects. Nowadays, pharmaceutical companies are developing more potent FGFR TKIs.

This review is an overview on the ongoing trials involving antiFGF-FGFR therapies (Wu et al., 2013).

\section{Pathway}

\subsection{Fibroblast growth factor}

Fibroblast Growth Factors (FGFs) include over 20 molecules that signal regulated by four transmembrane FGF receptors. An another FGF receptor 5 which has no potential activity of tyrosine kinase and is considered negatively control signaling through dimerizing with FGF receptors 1-4 (Markus Wiedemann, 2000). These FGFs are grouped in 7 subfamilies according to their phylogeny: FGF1 (FGF1 and FGF2), FGF4 (FGF4, FGF5 and FGF6), FGF7 (FGF3, FGF7,
FGF10 and FGF22), FGF9 (FGF9, FGF16 and FGF20), FGF8 (FGF8, FGF17 and FGF18), FGF15/19 (FGF15/19, FGF21 and FGF23) and FGF11 (FGF11, FGF12, FGF13 and FGF14). The first five are called as canonical (secreted; also known as paracrine FGFs) FGFs whereas FGF15/19 corresponds to the endocrine FGFs and FGF11 to intracellular FGFs. Canonical FGFs interact with HS as a cofactor for the activation of FGFR while FGF15/19 subfamily have the Klotho family protein as cofactor and FGF11 subfamily serve as cofactors for voltage gated sodium channels. Their pattern and timing of expression varies from tissue to tissue as some FGFs are expressed only in embryonic development while others are expressed in embryonic and adult tissues (Ornitz and Itoh, 2015). Therefore, FGFs play an important role during development and adult life. The activation of FGFR by FGF binding triggers cellular processes, such as cell proliferation, growth, differentiation, migration, and survival (E.M. Haugsten et al., 2010a; Haugsten et al., 2010b).

\subsection{FGFR - fibroblast growth factor receptor}

FGFRs have a canonical tyrosine kinase receptor structure, composed of three extracellular Immunoglobulin (Ig)-type domains (IgI, IgII, IgIII) with IgII and IgIII forming the FGF ligand-binding site pocket, composed of acidic residues between IgI and IgII (the acidic box), a single pass transmembrane domain and an intracellular tyrosine kinase domain (Lu et al., 2008b). Four different genes encode the FGFR family. Alternative splicing of 8-9 exons generate two different isoforms (b/c) of the D3 (IgIII) domain in each of the FGFR1, FGFR2 and FGFR3 except for the FGFR4 gene, which does not show any splicing activity, thus there are 7 different FGF receptors (Fig. 1). This is of considerable interest since it has been demonstrated that the $b$ isoforms are more expressed in epithelial tissue while the $c$ one in the mesenchymal tissue (Eswarakumar et al., 2005). These isoforms are tissue specific and show different affinity for FGF ligands (Johnson and Williams, 1992). Recently another receptor FGFR5 was discovered, which can bind FGFs with high 


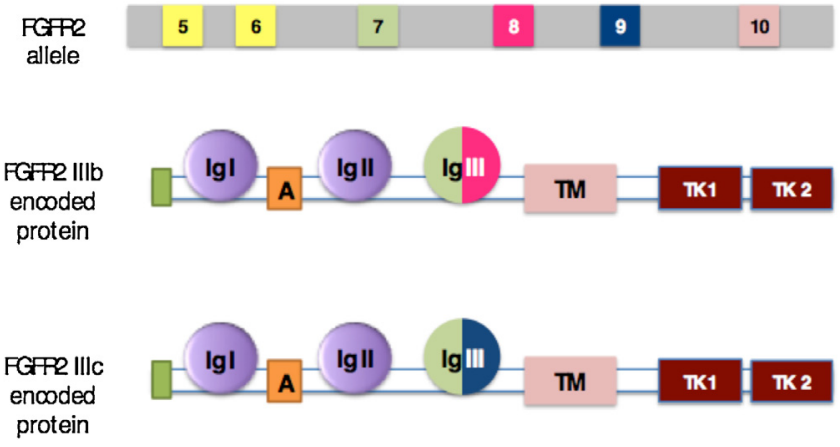

Fig. 1. The FGFR family is encoded by 4 different genes. The Ig III in FGFRs $1-3$ is encoded by two of the three exons 7, 8 and 9, producing different domains designated IIIa, IIIb and IIIc. This figure shows FGFR isoforms generated by alternative splicing of exons 8 and 9 . The $\mathrm{N}$ terminal half of the Ig III consists of the IIIa sequence while the $C$ terminal half is encoded by exon 8 (isoform IIIb) or exon 9 (isoform IIIc). FGFR: fibroblast growth factor receptor, Ig: immunoglobulin.

affinity, but lacks the intracellular tyrosine kinase domain (Gong, 2014).

During embryonic development FGFR pathway activation plays a fundamental role in mesenchymal-epithelial communication and in the organogenesis of nervous system, limbs, midbrain, lung and mammary gland (Lu et al., 2008a; Powers et al., 2000). During the adult life FGFR signal pathway contribute in regulation of other growth factor such as vascular endothelial growth factor (VEGF) and hepatocyte growth factor (HGF), playing an important role in tissue repair, angiogenesis and inflammation (Murakami et al., 2009; Powers et al., 2000).

\subsection{FGF/FGFR signaling pathway}

The signaling of FGF has a crucial role in both the adult and embryonic development. The signaling pathway of FGF is frequently hijacked through cancer cells, including different cancer types (Sleeman et al., 2001). The FGFR is a tyrosine kinase receptor, thus once the ligand binds to the receptor causes the dimerization of their intracellular domains. This changing in the intracellular structure leads to an autophosphorylation of tyrosine residues that causes the activation of several downstream transduction pathways (Haugsten et al., 2010a; Haugsten et al., 2010b). When the intracellular domain of the receptor is phosphorylated, it activates pathways that lead to the further expansion of the signal. It can be transmitted through two mechanisms, or using adapter proteins, or directly by binding transcription factors. In the first mechanism the phosphorylated tyrosine residues serve as docking sites for the adaptor proteins which are directly phosphorylated by FGFR: FGFR substrate 2 (FRS2) and Phospholipase- $\gamma$ (PLC- $\gamma$ ). FRS2 leads to the activation of Ras-dependent Mitogen Activated Protein Kinase (MAPK) and the Ras-independent Phospoinositide3-Kinase (PI3K)/AKT pathways. In turn, PLC- $\gamma$ stimulates Protein Kinase C (PKC) which helps to increase the MAPK pathway signal by phosphorylating Raf (Lew et al., 2009; Peng et al., 2009). The second mechanism lead to the cell activation through other signaling molecules, such as Shb (Src Homology 2 domain-containing transforming protein B), Src kinase, STATs (Signal Transducers and Activators of Transcription), Crk and RSK (Ribosomal S6 protein Kinase), among others (Gotoh, 2008). Interestingly, it has been demonstrated that FGF/FGFR signaling pathways are strongly regulated by feedback mechanisms: SPRoutY (SPRY), which is induced by FGF, down-regulates the activation of Growth Factor Receptor-Bound Protein (GRB2) working as a GRB2 competitor; MAPK Phosphatase 3 (MKP3) attenuates MAPK signaling because it dephosphorylates ERK1 and ERK2; Similar Expression to FGF(SEFs), a group of binding substrate competitor molecules (Lew et al.,2009) (Fig. 2).

\section{FGFR in cancer}

The first evidences about alterations in the FGF/FGFR pathway were discovered in metabolic diseases such as craniosynostosis, achondroplasia and hypogonadotropic hypogonadism. Nowadays it is known that mutations identical to those present in these diseases can be detected in tumor cells.

A recent study comparing more than 4800 tumor tissue samples has shown that $7.1 \%$ of all tumor types have genetic alterations in the FGF-FGFR axis. The aberrations percentages were analyzed for the different FGFRs subfamilies, showing that the most frequent alterations affects FGFR1 (49\%) followed by FGFR3 (23\%) and FGFR2 (19\%), with FGFR4 being the least affected (7\%). Furthermore, a small range of patients presented with multiple aberrations (5\%). The FGFR family alterations are more common in women than in men (17.6\% vs $10.0 \%$ ). This data is of great scientific value because it shows that an alteration of this pathway is the third most present after TP53 and KRAS anomalies (Harding and Nechiporuk, 2012; Helsten et al., 2015).

\subsection{FGFR alterations in cancer}

\subsubsection{Gene amplification}

Amplification of FGFR is reported to be present in $66 \%$ of cancers with an FGFRs alteration, with FGFR1 amplification being the most common (42\%) (Helsten et al., 2015). Approximately $20 \%$ of the squamous cell carcinomas (SCC) of the lung present with FGFR1 amplification and this has been shown to be associated with smoking in a dose-dependent fashion (Rooney et al., 2016). Recently a meta-analysis showed that patients with FGFR gene amplification have a worse prognosis than FGFR wild-type patients. This gene alteration is also observed in other tumors like breast cancer (14\%), urothelial cancer (7\%) and ovarian cancer (5\%) and squamous cell lung cancer (SCCL) (18.2\%) (Chang et al., 2014; Craddock et al., 2013; Heist et al., 2012; Kim et al., 2016a; Kim et al., 2016b; Monaco et al., 2016). In lung squamous cell carcinoma the presence of FGFR1 amplification doesn't change the patients' prognosis (Craddock et al., 2013). In another study it as been reported that FGFR1 is an independent negative prognostic factor in surgically resected SCCL and is associated with cigarette smoking (Kim et al., 2016a; Kim et al., 2016b). In gastric cancer, FGFR2 amplification was detected in $4.2-7.4 \%$ of cases and has been correlated with poor prognosis and lymphatic invasion (Su et al., 2014). Recently a study screened 312 gastric cancer patients demonstrating that FGFR2 amplification is correlated with a metastatic status at the diagnosis and a poor prognosis (Ahn et al., 2016). In the last two decades, invasive breast cancer samples have been screened extensively for FGFR amplifications, as they account for $7.5-17 \%$ of all breast cancer and $16-27 \%$ of luminal B-type breast cancer, in both cases reducing the patients' outcome. Among $10-18 \%$ of the samples showed FGFR amplification, again with FGFR1 amplification being the most frequent (8-10\%) (André and Cortés, 2015; Criscitiello et al., 2015; Helsten et al., 2015). In non-small cell lung cancer (NSCLC), the different histotypes are being screened for FGFR amplifications. It has been shown that FGFR1 amplifications are significantly correlated with tumor histotype: FGFR1 amplification is more common in SCC (20.7\%) than in large cell carcinoma (LC) (13\%) and adenocarcinoma (AC) (2.2\%) (Helsten et al., 2015). Interestingly it has been shown that FGFR1 amplification is much more represented in early stages than in advanced stages, suggesting a key role of FGRF1 amplification during the initial phase of tumor development which may be clinically important for treatment purpose 


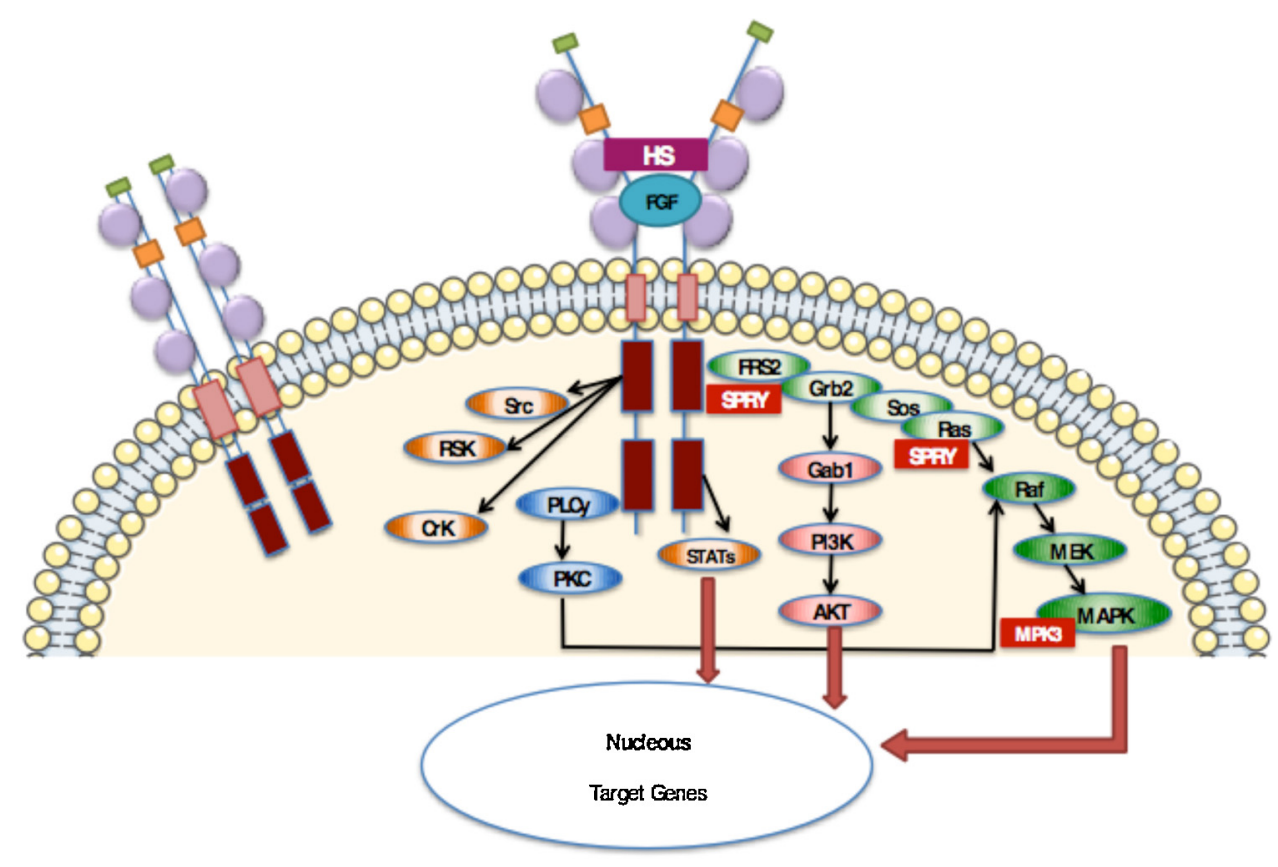

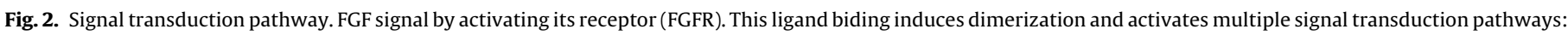

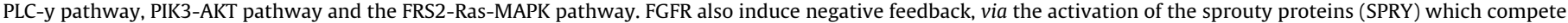
with Grb2, preventing Ras activation or directly biding to Ras. FGF: fibroblast growth factor.

(Cihoric et al., 2014; Helsten et al., 2015). Recently it has been discovered a high overexpression of FGFR1 in HNSCC (Head and neck squamous cell carcinoma) in particular, it was positive in $82 \%$ of human papillomavirus (HPV)-positive HNSCC and $75 \%$ of HPV-negative HNSCC and relates with poor outcome (Koole et al., 2016). Recently a meta-analysis of 24 studies reported that the outcome of FGFR gene amplified cancers have a worse prognosis than the patients without a FGFR amplification (Chang et al., 2014).

\subsubsection{Gene mutation}

Recent studies have shown that $26 \%$ of the detected FGFR aberrations are point mutations (Helsten et al., 2015). FGFR are the kinase genes most frequently mutated in several types of human cancers and different mutations have been described in all four FGFRs:

FGFR1: Two point mutations (N546K and K656E) have been described in vitro to affect the intracellular domain of the receptor and act as activating mutations (Hart et al., 2000; Lew et al., 2009). Nevertheless, no data is available on the incidence of these mutations in tumor samples.

FGFR2: 12 mutations have been described in the COSMIC database, but only seven of them are activating mutations, with N549K, S252W and P253R being the most common (Helsten et al., 2015). For example, the targetable $S 252 \mathrm{~W}$ mutation has been found that in $12 \%$ of endometrial cancer cells (Dutt et al., 2008).

FGFR3: Up to 13 different point mutations are reported in the COSMIC database, S249C being the most frequent. FGFR3 mutations are one of the most frequent FGFR alterations found in bladder cancer, interestingly it is more present in low-grade urothelial tumors than in the high-grade tumors (Pandith et al., 2008).

FGFR4: Only 5 known mutations of FGFR4 are described in kinase domain. There are two specific mutations of the FGFR4 kinase domain (K535 and E550) that causes autophosphorylation and constitutive activation. Such mutations have been identified in childhood rhabdomyosarcoma (RMS) (Helsten et al., 2015; Sun et al., 2015).

\subsubsection{Gene fusion}

A gene fusion is a joining between two different genes; either by translocation or inversion. It generates a deregulated hybrid protein allowing the cell to become neoplastic. FGFR gene rearrangements account for 8\% of FGFR aberrations (Helsten et al., 2015). FGFR2 and FGFR3 are the most frequently involved genes in this kind of alteration. They commonly fuse to the TACC3 (Transforming Acidic Coiled-Coil Containing Protein 3) gene, leading to a FGFR-TACC fusion protein with constitutive activation (Nelson et al., 2016; Parker et al., 2014). This gene fusion is very common in haematological malignancies, but there is also evidence of its occurrence in solid tumors (Capelletti et al., 2014). Up to $15 \%$ of the patients with multiple myeloma (MM) exhibit a $(4 ; 14)$ translocation which leads to the overexpression of FGFR3 (Chesi et al., 2001).

\section{Therapeutics opportunities against FGFR}

At present, the FGFR inhibiting molecules can be divided in two groups: Non-selective FGFR TKIs and Selective FGFR TKIs. The first group is related to multi-target TKIs that include FGFR in their targets and the second group corresponds to highly selective FGFR TKIs. Furthermore, another two classes of drugs have been investigated for FGFR inhibition: monoclonal antibodies and FGF-ligand traps.

\subsection{Non-selective FGFR TKIs}

Different chemotherapeutic agents have been synthesized for the management and treatment of several cancer types; although, no single or combination therapy treatment is effective particularly. A notable array of compounds have been described in recent years to (partially) inhibit FGFR, next to other Tyrosine Kinase Receptor (TKR), including Vascular Endothelial Growth Factor Receptor (VEGFR), Platelet Derived Growth Factor Receptor (PDGFR), Fms-like tyrosine kinase 3 (FLT-3), c-Kit (c-KIT), Rearranged during transfection (RET) and BCR-ABL. These compounds include Brivatinib (Cai et al., 2008), Lenvatinib (Yamamoto et al., 2014), Regorafenib (Wilhelm et al., 2011), Ponatinib (Gozgit et al., 
Table 1

Clinical trials involving multi-target TKI inhibitors with FGFR status based patient selection.

\begin{tabular}{|c|c|c|c|c|}
\hline Drug & Tumor & Phase & FGFR Criteria & Clinical Trial Identifier \\
\hline \multirow[t]{11}{*}{ Dovitinib (TKI258) } & Renal & II & FGFR1-2-3 amplification & NCT01791387 \\
\hline & \multirow[t]{2}{*}{ Urothelial } & II & FGFR3 mutations & Milowsky et al., 2014 \\
\hline & & II & FGFR3 mutation or over-expression & NCT01732107 \\
\hline & \multirow[t]{2}{*}{ Endometrial } & II & FGFR2 mutation & Konecny et al., 2015 \\
\hline & & II & FGFR2 mutation & NCT01379534 \\
\hline & Multiple myeloma & II & FGFR3 translocation & Scheid et al., 2015 \\
\hline & Prostate & II & FGFR1 over-expression & Wan et al., 2014 \\
\hline & \multirow[t]{2}{*}{ Gastric and GIST } & II & FGFR2 amplification & NCT01719549 \\
\hline & & I & FGFR2 & NCT02268435 \\
\hline & NSCLC & II & FGFR1 amplification & NCT01861197 \\
\hline & Tumor with FGFR pathway alteration & II & Any pathway alteration & NCT01831726 \\
\hline \multirow[t]{4}{*}{ Lucitanib (E-3810) } & \multirow[t]{2}{*}{ Breast } & II & FGFR1 amplification & NCT02053636 \\
\hline & & II & FGFR1 amplification & NCT02202746 \\
\hline & Lung & II & any FGFR1-3 alteration & NCT02109016 \\
\hline & Solid tumors & $\mathrm{I} / \mathrm{II}$ & FGFR1 amplification & NCT01283945 \\
\hline \multirow[t]{4}{*}{ Ponatinib (AP24534) } & Head and Neck & II & FGFR amplification and mutation & NCT01761747 \\
\hline & Endometrial & II & FGFR2 mutation & NCT01888562 \\
\hline & Biliary & II & FGFR2 fusion & NCT02265341 \\
\hline & Refractory metastatic cancers & II & any FGFR alteration & NCT02272998 \\
\hline \multirow[t]{8}{*}{ Nintedanib (BIBF 1120) } & \multirow[t]{2}{*}{ NSCLC } & 0 & FGFR1-3 alteration & NCT02299141 \\
\hline & & II & FGFR1 amplification & NCT01948141 \\
\hline & \multirow[t]{3}{*}{ Lung SCC } & \multirow[t]{3}{*}{ II } & \multirow[t]{3}{*}{ FGFR1 amplification } & NVALT- \\
\hline & & & & Grupo español \\
\hline & & & & Cancer de pulmón \\
\hline & Urothelial & II & FGFR3 mutation or over-expression & NCT02278978 \\
\hline & Breast & I & FGFR 1 & NCT02619162 \\
\hline & Solid tumors & I & FGFR 1 & NCT01349296 \\
\hline \multirow[t]{2}{*}{ Pazopanib (GW786034) } & \multirow[t]{2}{*}{ Solid tumors } & \multirow[t]{2}{*}{ II } & \multirow[t]{2}{*}{ FGFR2 amplification and mutation } & NCT02450136 \\
\hline & & & & NCT02691767 \\
\hline
\end{tabular}

HCC: Hepatocellular carcinoma; NSCLC: Non Small Cell Lung Cancer; SCLC: Small Cell Lung Cancer; CRC: Colorectal Cancer.

2012), Dovitininb (Porta et al., 2015), Nintedanib (Dhillon, 2015), Pazopanib (Prince et al., 2009), Orantinib (Ohta et al., 2009), ENMD 2076 (Matulonis et al., 2013), Lucitanib (Bello et al., 2011), PBI 05204 (Hong et al., 2014), Sunitinib (Welti et al., 2011) and Cediranib (Wedge et al., 2005). Although some of them have achieved approval for use against several cancer types, this section only focuses on those multi-target inhibitors that have included a subset of patients with FGFR alterations (Table 1).

\subsubsection{Dovitinib}

Dovitinib has been reported to target FGFR1, VEGFR, PDGFR $\beta$, cKit, and FLT3 (Porta et al., 2015). In vitro studies have reported that Dovitinib could be used in colorectal cancer (CRC) with KRAS + or $\mathrm{BRAF}+$ mutation. It has shown promising results in CRC with KRAS mutated because of increased expression of FGFR1 when compared to CRC BRAF mutated (increased expression of FGFR3) (Lee et al., 2015). In breast cancer, Dovitinib demonstrated anti-tumor activity in FGFR-amplified breast cancer cell lines (André et al., 2013). In advanced thyroid cancer the commonest treatmentrelated adverse events were diarrhoea, anorexia, vomiting, fatigue and nausea, most of which were grade 1 or 2 (Lu et al., 2008c). In a Phase II clinical trial in patients with advanced squamous nonsmall cell lung cancer with FGFR1 amplification, Dovitinib showed an ORR of $11.5 \%$ (95\% CI, 0.8-23.8) and Disease Control Rate (DCR) of 50\% (95\% CI, 30.8-69.2) (Myung-Ju et al., 2016). Preclinical activity also showed weak activity of Dovitinib against FGFR2 and 3. Dovitinib was tested as second-line treatment in urothelial cancer patients classified according to the presence or absence of FGFR3 point mutations, with poor activity regardless of the mutation profile (Milowsky et al., 2014). Recently, this compound has shown no differences in response rate in second-line treatment in metastatic endometrial cancer patients that were classified according to presence or absence of FGFR2 mutations (Konecny et al., 2015). The $t(4,14)$, that affects FGFR3 expression, was considered as selection criteria in a phase II clinical trial in multiple myeloma patients (Chesi et al., 2001). Despite showing no single agent activ- ity, patients with this kind of translocation showed a higher rate of disease stabilization and longer progression free survival (PFS), $90 \%$ of patients had adverse effects such as diarrhoea, nausea, vomiting, and fatigue (Scheid et al., 2015). Promising results have been shown in men with prostate cancer with bone metastases and an alteration of FGFR1, although no other studies have confirmed these results (Wan et al., 2014). Recently a phase II clinical trial in patients with advanced squamous non-small cell lung cancer with FGFR1 amplification has shown $11.5 \%$ of overall response rate, and the most common grade of adverse effects was 3 or higher for fatigue, anorexia and hyponatremia (Lim et al., 2016a; Lim et al., 2016b). A phase I clinical trial has been performed to investigate the safety of Dovitinib in recurrent glioblastoma. Seventy-two adverse events occurred and $16.7 \%$ of them were classified as $\geq$ grade 3 toxicity. The recommended phase II dose was $300 \mathrm{mg}$ (Schäfer, 2016). A phase II trial tested Dovitinib against Sorafenib in Hepatocellular carcinoma but the activity of Dovitinib was not superior than Sorafenib (Cheng et al., 2016).

Still, several studies are ongoing with different types of cancer to evaluate the efficacy of this drug: gastric cancer (NCT01719549), urothelial (NCT01732107), advanced NSCLC and CRC (NCT01676714), renal cell carcinoma (NCT01791387) and pancreatic and hepatobilliary cancer (NCT01497392).

\subsubsection{Lenvatinib}

Lenvatinib is a multi-targeted TKI of VEGFR1-3, FGFR1-4, platelet-derived growth factor receptor $\alpha$ (PDGFR $\alpha$ ), RET and KIT. This drug is approved in 2015 by the FDA and EMA for patients with metastatic, progressive, radioactive iodine-refractory differentiated thyroid carcinoma based on a phase II clinical trial. Adverse effects were present in $>50 \%$ of patients, hypertension, diarrhoea, fatigue/asthenia, and decreased appetite were the most frequent (Cabanillas et al., 2015). Currently, this drug is being tested in a phase $1 / 2$ study in children and adolescents with refractory or relapsed solid malignancies (NCT02432274). 


\subsubsection{Nintedanib}

Nintedanib is a non selective FGFR TKI that targets FGFR1-3, VEGFR1-3, PDGFR and Flt3. Promising results with this multitarget inhibitor were obtained in a wide range of cancers including lung, prostate, colorectal, hepatocellular carcinoma and in gynaecological tumors. Currently, it has received the EMA approval for its second-line use in combination with Docetaxel for lung adenocarcinoma based on the results of the LUME-Lung 1, which showed an improvement in PFS (median 3.4 months [95\% CI 2.9-3.9] vs 2.7 months [2.6-2.8]; HR 0.79 [95\% CI 0.68-0.92], $p=0.0019)$ and overall survival (12.6 months [95\% CI 10.6-15.1] vs 10.3 months [95\% CI 8.6-12.2]; HR 0.83 [95\% CI 0.70-0.99], $\mathrm{p}=0.0359$ ), independently of the FGFR status (Reck et al., 2014). The pre-clinical efficacy of Nintedanib and the prognostic role of FGFR alteration have been investigated in a recent study showing that FGFR alterations are detectable in $20 \%$ of lung squamous cell cancer (LSCC) by Next Generation Sequencing (NGS). In this study, 75 LSCC tissue specimens were evaluated, the prognosis of the specimens harboring FGFR alterations were significantly worse when treated with Nintedanib (Hibi et al., 2016). Currently, a pilot study of Nintedanib in molecularly selected patients with advanced NSCLC is ongoing. This study will recruit patients with advanced NSCLC with aberrations in RET and in Nintedanib target genes: VEGFR1-3, TP53, PDGFR-A, PDGFR-B, and FGFR1-3. Some studies with Nintedanib are still ongoing in breast cancer (NCT02619162), NSCLC (NCT01948141), neuroendocrine tumors (NCT02399215) and urothelial cancer (NCT02278978).

\subsubsection{Ponatinib}

Ponatinib is a multi-target TKI of Bcr-Abl, VEGFRs, FGFRs, TIE2 and Flt3 approved for chronic myeloid leukaemia (CML). It has been demonstrated that Ponatinib can inhibit the activation of cells with the BCR-ABL T315I mutation, which has been reported to confer resistance to Imatinib (Zhou et al., 2011). Moreover, an in vitro study has been analyzing the possibility of using Ponatinib in cancer cell lines of endometrial, bladder, gastric, breast, lung and colon cancer harboring FGFR1-4 alterations. The results are very promising since Ponatinib shows specific activity against the four receptors and it seems to work like a FGFR-pan-inhibitor (Gozgit et al., 2012). Currently, they are trying to discover novel Ponatinb anologues to reduce kinase insert domain receptor (KDR) activities (Yang et al., 2017) (I would delete this sentence). This drug is still being tested in three phase II trials in biliary cancer (NCT02265341), lung cancer (NCT01935336) and solid tumors with several activating mutations including FGFR alterations (NCT02272998).

\subsubsection{Lucitanib}

Lucitanib is a strong inhibitor of the FGFR1/2, VEGFR1-3 and $\operatorname{PDGFR} \alpha / \beta$. The most common adverse effects were proteinuria, hypertension and asthenia (Soria et al., 2014). In a phase I/II clinical trial it has been tested in several tumors such as breast, colon, lung and thyroid, the Maximum Tolerated Dose (MTD) being $15 \mathrm{mg}$ a day. In the FGF-aberrant group, the objective response rate (ORR) was 30.4\% (95\% CI 15.60-50.87) and median PFS was 32.1 weeks (95\% CI 9.7-56.1). Furthermore, in subgroup with FGFaberrant breast cancer, the results were even better: ORR 50\% (95\% CI 23.38-74.62) and PFS 40.4 weeks (95\% CI 9.7 to -). Currently, there is a phase II with metastatic breast cancer patients recruiting (NCT02053636) and two phase II trials are still ongoing in lung cancer (NCT02109016) and solid tumors, including FGFR alterations (NCT01283945).

\subsubsection{Pazopanib}

Pazopanib is a potent multi-target tyrosine kinase inhibitor working against VEGFR1-3, PDGFR $\alpha \beta$, and c-kit (Sonpavde et al., 2009). Currently it has been approved for renal cell carcinoma (RCC) and soft tissue sarcoma but selection criteria do not include FGFR aberrations. Recently, a review tried to analyze pharmacokinetic variability and potential pharmacokinetic drug-drug interaction and it has shown that more studies are needed to guide dose regimens in target populations (Boudou-Rouquette et al., 2016). As far as we know, there is no information about its activity against FGFR, therefore, a new clinical trial has been initiated with the aim of more substantial proof (Table 1 ).

\subsection{Selective FGFR TKIs}

Several molecules have been described in recent years to act as selective inhibitors of the whole FGFR family. This includes AZD4547 (Gavine et al., 2012), BGJ398 (Guagnano et al., 2011), LY2874455 (Zhao et al., 2011), TAS-120 (Ochiiwa et al., 2014), ARQ 087 (Dransfield et al., 2014), PD 173074 (Dimitroff et al., 1999), JNJ42756493 (Tabernero et al., 2015), BLU9931 (Hagel et al., 2015), DEBIO 1347 (Nakanishi et al., 2014), FGF401 (Repana et al., 2015) and BAY-1163877 (Heroult et al., 2014). Due to the large amount of drugs we will only focus on those who are being evaluated in clinical trials (Table 2).

\subsubsection{AZD4547}

AZD4547 is an oral, small molecule that is showing good results in inhibiting the FGFR downstream pathway and inducing cytotoxic and cytostatic effects. These results are been demonstrated in tumor cell lines expressing different kinds of FGFR alterations. It has shown strong activity against FGFR1, FGFR2, FGFR3, FRS2, and PLC $\gamma$ (Gavine et al., 2012). This compound has also been reported to have highly selective activity in NSCLC cells selected for FGFR1 amplification, it induces tumor stasis and regression in most (4/5) of the NSCLC patient-derived tumor xenograft (PDTX) models (Zhang et al., 2012). AZD4547 has shown promising in vitro results inhibiting cell growth in gastric cancer patient derived cell lines carrying the FGFR2 amplification; it demonstrated good anti-proliferative activity in an endometrial cell line harboring the FGFR2-K310R/N550K mutations. Furthermore, AZD4547 inhibited colorectal cancer cell growth with a high expression of FGFR12 with cytotoxic and pro-apoptotic effects (Kwak et al., 2015; Lu et al., 2008d; Yao et al., 2015). A phase II proof of concept study in patients with FGFR1 (HER2 negative breast cancer [BC]/NSCLC) and FGFR2 (gastroesophageal cancer [GC]) amplified tumors demonstrated that AZD4547 has a higher activity in FGFR2 amplified GC (RR 33\%) compared to FGFR1 amplified BC (RR 12.5\%) (Smyth et al., 2015). Nowadays, it is one of the promising drugs for this kind of alteration, although conflicting results in different cell lines of the same tumor type point to an interfering factor. More research is warranted to determine the right selection criteria for this compound. Currently, there is a clinical trial in breast cancer recruiting patients (NCT01791985) that will evaluate if there is a relation between FGFR1 levels and the benefit from AZD4547.

\subsubsection{BGJ398}

This compound has obtained interesting results in endometrial cancer cell lines with FGFR2 mutations (S252W, N550K) inducing cell cycle arrest and cellular apoptosis (Konecny et al., 2013). BGJ398 also targets FGFR1 amplification/overexpression in pancreatic ductal adenocarcinomas (PDACs), unfortunately only a minority of PDACs harbor FGFR1 amplification (Lehnen et al., 2013). BGJ398 also demonstrated potential therapeutic efficacy in colorectal cancer cells with an FGFR1 amplification (Göke et al., 2013). In gastric cancer cells expressing FGFR1 and FGFR2IIIc it demonstrated efficacy by inhibiting growth, motility, c-MYC expression, VEGFA secretion and signaling (Schmidt et al., 2015). In a phase I study, BGJ398 presented an ORR 40\% and a DCR $100 \%$ in patients with urothelial cancer in the subgroup with FGFR alter- 
Table 2

Clinical trials involving Pan-inhibitors with FGFR status based patient selection.

\begin{tabular}{|c|c|c|c|c|}
\hline DRUG & Tumor & Phase & FGFR based eligibility & Clinical TrialsIdentifier \\
\hline \multirow[t]{10}{*}{ AZD 4547} & Gastric & II & FGFR2 amplification & NCT01457846 \\
\hline & NSCLC & $\mathrm{I} / \mathrm{II}$ & FGFR1 amplification & NCT01824901 \\
\hline & & II & FGFR pathway alteration & NCT02664935 \\
\hline & Urothelial & $\mathrm{Ib}$ & FGFR3 mutation and FGFR1-3 gene fusions & NCT02546661 \\
\hline & Advanced solid tumors & I & FGFR1/2 amplification & NCT00979134 \\
\hline & & II & FGFR 1-3 Amplificación & NCT02465060 \\
\hline & Squamous cell lung & II/III & FGFR1-3 mutation & NCT02154490 \\
\hline & & & & NCT02965378 \\
\hline & Breast & $\mathrm{I} / \mathrm{II}$ & FGFR1 amplification & NCT01202591 \\
\hline & Glioma & $\mathrm{I} / \mathrm{II}$ & FGFR-TACC gene fusion & NCT02824133 \\
\hline \multirow[t]{7}{*}{ BGJ 398} & Solid tumors & $\mathrm{Ib}$ & FGFR1-3 alteration & NCT01928459 \\
\hline & & II & FGFR1-3 alteration & NCT02160041 \\
\hline & & I & FGFR3 Mutation or Fusion/FGFR1-2 Amplification & NCT01004224 \\
\hline & Cholangiocarcinoma & II & FGFR2 fusion or any FGFR alteration & NCT02150967 \\
\hline & GBM & II & FGFR gene fusion or mutation & NCT01975701 \\
\hline & Urothelial & (not provided) & FGFR3 & NCT02657486 \\
\hline & HNSCC & II & FGFR1-3 amplification & NCT02706691 \\
\hline TAS-120 & Advanced cancers or MM & $\mathrm{I} / \mathrm{II}$ & FGFR alteration & NCT02052778 \\
\hline ARQ-087 & Advanced solid tumors & $\mathrm{I} / \mathrm{II}$ & FGFR alteration & NCT01752920 \\
\hline \multirow[t]{5}{*}{ JNJ-42756493 } & Urothelial & II & Any FGFR alteration & NCT02365597 \\
\hline & Multiple Myeloma & II & FGFR3 mutation & NCT02952573 \\
\hline & Solid tumors or & $\mathrm{I}$ & Any FGFR alteration & NCT01703481 \\
\hline & Lymphoma & & & NCT01962532 \\
\hline & & II & Any FGFR alteration & NCT02699606 \\
\hline DEBIO 1347 & Advanced solid tumors & $\mathrm{I}$ & FGFR1-3 alteration & NCT01948297 \\
\hline \multirow[t]{2}{*}{ BAY-1163877 } & Solid tumors & I & FGFR over-expression/mutation & NCT01976741 \\
\hline & Neoplasms & I & FGFR over-expression or FGFR3 mutation & NCT02592785 \\
\hline
\end{tabular}

HCC, Hepatocellular carcinoma; NSCLC, Non Small Cell Lung Cancer; CRC, Colorectal Cancer; MM, Multiple Myeloma; GBM, Glioblastoma multiforme.

ation (Lecia et al., 2014). In a cholangiocarcinoma patient derived xenograft (PDX) mouse model bearing an FGFR2-CCDC6 fusion protein from a metastatic lung nodule were tested for ponatinib, dovitinib and BGJ398. BGJ398 appeared to be superior in FGFRinhibiting potency (Wang et al., 2016). In a phase I clinical trial in patients with advanced solid tumors harboring genetic FGFR alterations, BGJ398 proved antitumor activity, good tolerability and manageable safety profile (Nogova et al., 2016). This compound is being tested in several clinical trials in patients with solid tumors (NCT02160041; NCT01004224; NCT01928459), cholangiocarcinoma (NCT02150967) and glioblastoma (NCT01975701).

\subsubsection{TAS -120}

TAS-120 is a selective irreversible FGFR pan-inhibitor that has been reported to show specific activity against FGFR amplification in preclinical models (Ochiiwa et al., 2014). It is currently being assessed in advanced solid tumors or MM according to the FGFR profile (NCT02052778).

\subsection{4. $A R Q-087$}

This pan-FGFR inhibitor has shown preliminary antitumor activity together with manageable adverse effects $(G<2)$ in a Phase I clinical trial with tumors harboring FGFR amplifications (Kyriakos et al., 2015). Preclinical activity of ARQ-087 was tested in a group of different cancers cell lines showing positive relation between ARQ087 concentration and cancer cell death (Hall et al., 2016). Currently there are not a lot of data on this drug but the latest studies have shown specific activity inducing cell cycle arrest and apoptosis correlated to the level of FGFR2, a clinical development plan including a patient selection strategy is defined and the drug is currently in a Phase I/II clinical trial (NCT01752920).

\subsubsection{JNJ 42756493}

JNJ 42756493 was tested in vitro and in vivo in CRC cell lines with FGFR wild-type or FGFR2 amplification, it induced cell death and decreased cell survival in the cell lines with the highest expression of FGFR2 (Verstraete et al., 2015). A phase I clinical trial in advanced solid tumor is being carried out to assess MTD in solid tumors and lymphomas (Tabernero et al., 2015).

\subsubsection{DEBIO 1347}

This pan-FGFR inhibitor has shown great selectivity in a wide panel of cell lines and also in in vivo models with FGFR alterations, DEBIO 1347 is of great interest because it can inhibit a gatekeeper FGFR2 mutation (V564F) that cause resistance to other drugs (AZD4547 or dovitinib, for example) (Nakanishi et al., 2014). A phase I study in advanced solid tumors is currently being carried out (NCT01948297).

\subsubsection{BAY-1163877}

Preclinical models have marked this compound as a potent and selective FGFR1-3 inhibitor. BAY-1163877 induced reduction of cell growth by $67 \%$ to $92 \%$ in lung and esophageal SCC xenograft model with FGFR1-overexpression, and FGFR3-overexpressing head and neck SCC xenograft model (Héroult et al., 2015; Heroult et al., 2014). Two phase I clinical trials are assessing its activity in FGFR altered solid tumors and neoplasms (NCT01976741; NCT02592785).

\subsubsection{FGF 401}

Preclinical data showed that FGF401 selectively binds to FGFR4. There is limited data about this compound. Currently, patients are being recruited for a Phase I/II clinical trial in order to evaluate FGF 401 safety and efficacy (NCT02325739).

\subsection{Antibodies against FGFs and FGFRs and FGF-ligand TRAP}

The development of antibodies that target exclusive members, or even isoforms of a receptor has attracted much interest in recent years. Several different $m A b$ have been developed to target components of the FGF-FGFR axis: GP369 (Bai et al., 2010), GAL-FR21 (Zhao et al., 2010), GAL-FR22 (Inokuchi et al., 2015), GAL-F2 (Wang et al., 2012), MFGR1877S (Fauvel and Yasri, 2014), hLD1.vb (Bumbaca et al., 2011), FP-1039 (Marshall et al., 2011), R3Mab (French et al., 2012), PRO-001 (French et al., 2012), 1A6 (Pai et al., 2008) and LD1 
Table 3

Clinical trials involving Monoclonal Antibodies with FGFR status based patient selection. HNSCC: Head Neck Squamous Cell Carcinoma; MM: Multiple Myeloma.

\begin{tabular}{|c|c|c|c|c|}
\hline Drug & Target & Tumor & Phase & Clinical TrialsIdentifier \\
\hline \multirow[t]{3}{*}{ MFGR1877S } & FGFR3 & Bladder & I & Fauvel et al., 2014 \\
\hline & & MM & I & NCT01122875 \\
\hline & & Solid tumors & I & NCT01363024 \\
\hline \multirow[t]{3}{*}{ FP-1039 } & FGF Ligand trap & Solid tumors & I & NCT01868022 \\
\hline & & & & NCT00687505 \\
\hline & FGFR2 & Endometrial cancer & II & NCT01244438 \\
\hline
\end{tabular}

(French et al., 2012). Two main mechanisms of action have been considered; either blocking ligand binding (trap-ligand) or preventing receptor dimerization. However, only two of them have been considered for assessment in clinical trials: MFGR1877S and FP-1039 (Table 3).

\subsubsection{MFGR18775}

This mAb was the first that has been tested. It specifically binds FGFR3, thereby blocking the dimerization of the receptor. Unfortunately a phase I clinical trial was stopped due to poor results (Fauvel and Yasri, 2014). Two other phase I trials in MM and solid tumors with this $\mathrm{mAb}$ have been completed, with preliminary data showing no objective response in MM patients and prolonged periods of disease stability in some patients (Lu et al., 2008e; ODonnell et al., 2012).

\subsection{2. $F P-1039$}

FP-1039 (also known as GSK230) is the result of the fusion between FGFR1 and the Fc portion of a human IgG1. It acts as a ligand-trap, selectively binding to and neutralizing several FGFs ligands; FP-1039 inhibits tumor models such as FGFR1-amplified lung cancer and FGFR2-mutated endometrial cancer (Harding et al., 2013). One phase I study has been performed in advanced tumors. Because the patients were not preselected, this trial did not show an objective response. Its main goal was to analyze the tolerability and possible adverse effects with use in humans (Tolcher et al., 2016). Regarding this, FP-1039 demonstrated good tolerability and few toxicities such as urticaria, neutropenia and muscular weakness at the limiting doses of $0.75 \mathrm{mg} / \mathrm{kg}, 1 \mathrm{mg} / \mathrm{kg}$ and $16 \mathrm{mg} / \mathrm{kg}$ respectively (Tolcher et al., 2016). Another ongoing multi-arm phase Ib clinical trial is testing FP-1039/GSK3052230 (fusion protein GSK230) in combination with paclitaxel + carboplatin (arm A), in combination with docetaxel ( $\operatorname{arm} B$ ) or in combination with pemetrexed + cisplatin in metastatic squamous NSCLC patients with FGFR1 amplification (NCT01868022) (Garrido et al., 2015). Recently, FP-1039 has shown good activity in mesothelioma models providing a rationale for the use of this drug in a phase I clinical trial (Blackwell et al., 2016).

\subsection{Resistance to therapies}

There are no clinical reports regarding resistance mechanisms against FGFR inhibitors. This is linked to the novelty of FGFR as target for TKIs, with most of them currently being in early phase clinical trials (see Tables). However, several preclinical models have pointed to possible mechanisms of resistance against FGFR therapies. In MM cell lines, a gatekeeper mutation in FGFR3 (FGFR3 V555M) is involved in resistance to AZD4547 and PD173074 (both Pan-FGFR Inhibitors) (Chell et al., 2013). In endometrial cell lines, several FGFR2 point mutations (especially V564I) have been reported to confer different degrees of resistance to multi-target inhibitors (Dovitinib, Ponatinib and PD173074) (Byron et al., 2013). Moreover, a gatekeeper mutation in FGFR1 (V561M) has also been described in squamous cell lung cancer and breast cancer, suggesting that it could be involved in resistance to multi-target inhibitors like Lucitanib because but the same cell line maintained the sus- ceptibility to AZD4547 (which target the same mutation), that is due to a different construct-flexibility between the drugs, AZD4547 affinity is preserved by V561M FGFR1 due to a flexible linker that allows multiple inhibitor binding modes (Sohl et al., 2015). Another study has shown that epithelial-to-mesenchymal transition (EMT) confers resistance to selective FGFR inhibitors (AZD4547, BGJ398 and PD173074) in SNU-16R gastric cancer cells with FGFR2 amplification (Grygielewicz et al., 2014). In bladder cancer models with FGFR3 amplification, resistance to BGJ398 has been reported to involve both EMT and switching from FGFR to ERBB2/3 signaling pathway (Wang et al., 2015). Regarding the role of the FGFRpathway in resistance to other therapies, a retrospective study in osteosarcoma tumor tissue has detected that $20 \%$ of patients with FGFR 1 amplification had a poor response to chemotherapy as compared to patients without this alteration (Amary et al., 2014). Sinapsine, an alkaloid derived from cruciferous' seeds, downregulates FGFR4 (Guo et al., 2016). FGFR resistance to AZD3437 has been found in lung cancer cell lines (H1581AR) due to MET amplification by activating ErbB3, in the same experiment, Kim et al. found that a combination of a FGFR inhibitor and a Met inhibitor synergistically inhibited cell proliferation (Kim et al., 2016a; Kim et al., 2016b). In a small cell lung cancer group of patients with FGFR1 amplification treated with Nintedanib might occur a resistance. This specific resistance is induced by an overexpression of the multidrug-resistance transporter $\mathrm{ABCB}$, so, a strategy could be, use FGFR1 inhibitors with a drug that downregulates ABCB1 such as ETAR antagonist (Englinger et al., 2016). Recently, a study analyzed the most common FGFR alterations that cause resistance to therapy in preclinical models. FGFR3 N540 and K650 mutations, a gatekeeper mutation (FGFR3 V555M), and other mutations corresponding to FGFR3 I538V, FGFR2 N549H/T, FGFR2 K659N, FGFR1 V651M, FGFR4 V550L and V550E (typical in Rhabdomyosarcoma) and FGFR4 V550M (in breast cancer) are the most common alterations. In the future, it should be done more studies to reveal differential, drug-specific impact of different FGFR KD (Kinase Domain) mutations (Patani et al., 2016). Similarly to MET amplifation, an activation of EGFR has been identified in FGFR3-mutant bladder cancer as a mechanism of resistance. A combination of FGFR inhibitor (PD173074) and an EGFR inhibitor has a better antitumor activity than the single treatment given alone (Herrera-Abreu et al., 2013).

An interesting role of the FGFR has been identified in the tumor cells treated with EGFR inhibitors, first, an increasing of FGFR2 and FGFR3 mRNA were identified in a panel of NSCLC cell lines treated with EGFR TKI, leading to acquire a resistance to EGFR TKI (Ware et al., 2013). The same group showed an induction of FGF2 and FGFR1 as a mechanism of resistance to EGFR TKI in 3 of 7 NSCLC cell lines (Ware et al., 2010). More recently, a different group analyzed the EGFR TKI mechanism of resistance in NSCLC cell lines and they found a FGFR activation (FGF2 and FGFR1 were upregulated). The treatment inhibiting both pathways (EGFR and FGFR) improved the efficacy and might be a potential strategy to enhance antitumor activity (Azuma et al., 2014). In a group of 132 patients with NSCLC treated with an EGFR TKI, an alteration in FGFR1-3 has been found more frequently in the non-responders compared to responders (Lim et al., 2016a; Lim et al., 2016b). These findings have been found 
in colorectal cancer too, as well as, it has been found that an FGF9 upregulation leads to a strong resistance to anti-EGFR therapies (Mizumaki et al., 2016).

\section{Conclusions}

In this review we have shown that FGFR alterations are significantly present in several tumor types, offering a new opportunity to develop personalized therapy based on FGFR status. However, none of the drugs with multi-target TKI activity have the approval to be used as therapy based on the FGFR status. On the other hand, several clinical trials are currently ongoing to assess FGFR alterations as biomarker for patient inclusion in multi-target TKI clinical trials. As for the pan-inhibitors, selective FGFR-TKIs are showing promising results, although they are still in early phases of development.

At the moment the best results are on multi-target drugs such as Dovitinib, Lenvatinib and Nintedanib, but some of the selective FGFR TKIs inhibitors and Antibodies against FGFs and FGFRs and FGF-ligand TRAP show good preclinal results in inhibiting cell growth and proliferation. Since it has been already tested the efficacy and long-term safety of most of these new drugs in phase I clinical trials, phase II and IIII, it should be started, as soon as possible, clinical trials to test these drugs activity in preselected patients harboring a specific mutation in FGFR family pathway. Another fundamental direction is to investigate the combination of FGFR pathway inhibitors with other proliferative inhibitors such as EGFR and MET TKI to overcome the resistance mechanisms that can happen in a single targeted agent therapy.

Additionally, FGF-FGFR pathway has a role in the microenvironment of the tumor so, FGFR inhibitors could be drugs that potentiate the effects of other cancer therapies with activity in the tumor microenvironment such as the immune checkpoint inhibitors or anti-angiogenic therapies. Whereby, designing clinical trials with the combination of these drugs is warranted. We believe that FGFR is able to acquire a prominent role in the field of oncology in a short period of time and that their molecular analysis should be considered as a criteria for the therapy decision-algorithm.

\section{Expert opinion}

FGFR tyrosine kinase inhibitors are promising targeted therapy drugs in various types of cancer, although there are several challenges ahead. This family of receptors shares common intracellular signaling pathways with other TKR. Because of this, cancer cells tend to overcome the TKI inhibition by either selection of mutant forms of the TKR, or by switching to a parallel signaling pathway. Thus, in our opinion the future of the TKR inhibitors will come from the development of TKIs that target different TKRs simultaneously or other drugs with different mechanism of action, such as immunotherapy. In this context, understanding how the FGFFGFR axis interacts with other known altered TKR, such as EGFR and VEGFR, and their downstream pathways, is fundamental to develop molecular-driven therapeutic strategies that take into account the different signalization pathways. Another drawback is the lack of a molecular alteration that could predict response to the FGFR inhibitors. In our opinion it is essential to go deeper into the study of the molecular alterations (mutations, translocations or amplifications) of FGFR and its pathway, in order to validate molecular driver mutations, which will allow us to achieve better results with these targeted therapies. Nowadays the new high throughput technologies will provide new information to facilitate identification of new genetic alterations in molecules involved in the FGF-FGFR pathway and will be crucial for predicting a good response to targeted therapy. Other interesting directions are the reassessment of multi-target inhibitors considering the FGFR status of the tumor or to assess the use of FGFR TKIs on patients that show FGFR alterations and have developed resistance to other TKIs. In our opinion genetic studies should be included in clinical trials. We propose to perform exome sequencing at baseline and after progression in tumors with no clear driver mutations in order to better understand the role of FGFR as a potential biomarker in cancer treatment.

\section{Conflicts of interest}

All authors declare no conflicts of interest.

\section{References}

Ahn, et al., 2016. FGFR2 in gastric cancer: protein overexpression predicts gene amplification and high $\mathrm{H}$-index predicts poor survival. Mod. Pathol.

Amary, M.F., Ye, H., Berisha, F., Khatri, B., Forbes, G. Lehovsky, K., Frezza, A.M. Behjati, S., Tarpey, P., Pillay, N., Campbell, P.J., Tirabosco, R., Presneau, N., Strauss, S.J., Flanagan, A.M., 2014. Fibroblastic growth factor receptor 1 amplification in osteosarcoma is associated with poor response to neo-adjuvant chemotherapy. Cancer Med. 3, 980-987.

André, F., Bachelot, T., Campone, M., Dalenc, F., Perez-Garcia, J.M., Hurvitz, S.A., Turner, N., Rugo, H., Smith, J.W., Deudon, S., Shi, M., Zhang, Y., Kay, A., Porta, D.G., Yovine, A., Baselga, J., 2013. Targeting FGFR with dovitinib (TKI258): preclinical and clinical data in breast cancer. Clin. Cancer Res. 19, 3693-3702.

André, F., Cortés, J., 2015. Rationale for targeting fibroblast growth factor receptor signaling in breast cancer. Breast Cancer Res. Treat. 150, 1-8.

Azuma, K., Kawahara, A., Sonoda, K., Nakashima, K., Tashiro, K., Watari, K., Izumi, H., Kage, M., Kuwano, M., Ono, M., Hoshino, T., 2014. FGFR1 activation is an escape mechanism in human lung cancer cells resistant to afatinib, a pan-EGFR family kinase inhibitor. Oncotarget 5 (15), 5908-5919.

Bai, A., Meetze, K., Vo, N.Y., Kollipara, S., Mazsa, E.K., Winston, W.M., Weiler, S., Poling, L.L., Chen, T., Ismail, N.S., Jiang, J., Lerner, L., Gyuris, J., Weng, Z., 2010. GP369, an FGFR2-IIIb-specific antibody, exhibits potent antitumor activity against human cancers driven by activated FGFR2 signaling. Cancer Res. 70, 7630-7639

Beenken, A., Mohammadi, M., 2009. The FGF family: biology, pathophysiology and therapy. Nat. Rev. Drug Discov. 8, 235-253.

Bello, E., Colella, G., Scarlato, V., Oliva, P., Berndt, A., Valbusa, G., Serra, S.C., D'Incalci, M., Cavalletti, E., Giavazzi, R., Damia, G., Camboni, G., 2011. E-3810 is a potent dual inhibitor of VEGFR and FGFR that exerts antitumor activity in multiple preclinical models. Cancer Res. 71, 1396-1405.

Blackwell, C., Sherk, C., Fricko, M., Ganji, G., Barnette, M., Hoang, B., Tunstead, J., Skedzielewski, T., Alsaid, H., Junker, B.M., Kumar, R., DeYoung, M.P., Minthorn, E., 2016. Inhibition of FGF/FGFR autocrine signaling in mesothelioma with the FGF ligand trap, FP-1039/GSK3052230. Oncontarget 7 (26), 39861-39871.

Boudou-Rouquette, P., Tlemsani, C., Blanchet, B., Huillard, O., Juinot, O., Arrondeau, J., Thomas-Schoemann, A., Vidal, M., Alexandre, J., Goldwasser, F., 2016. Clinical pharmacology, drug-drug interactions and safety of pazopanib: a review. Expert Opin. Drug Metab. Toxicol. 12 (12), 1433-1444 [Epub 2016 Aug 24].

Brooks, A.N., Kilgour, E., Smith, P.D., 2012. Molecular pathways: fibroblast growth factor signaling: a new therapeutic opportunity in cancer. Clin. Cancer Res. 18, 1855-1862.

Bumbaca, D., Wong, A., Drake, E., Reyes, A.E., Lin, B.C., Stephan, J.-P., Desnoyers, L., Shen, B.-Q., Dennis, M.S., 2011. Highly specific off-target binding identified and eliminated during the humanization of an antibody against FGF receptor 4. MAbs 3, 376-386.

Byron, S.A., Chen, H., Wortmann, A., Loch, D., Gartside, M.G., Dehkhoda, F., Blais, S.P., Neubert, T.A., Mohammadi, M., Pollock, P.M., 2013. The N550K/H mutations in FGFR2 confer differential resistance to PD173074, dovitinib, and ponatinib ATP-competitive inhibitors. Neoplasia 15, 975-988.

Cabanillas, M.E., Schlumberger, M., Jarzab, B., Martins, R.G., Pacini, F., Robinson, B. McCaffrey, J.C., Shah, M.H., Bodenner, D.L., Topliss, D., Andresen, C., O'Brien, J.P. Ren, M., Funahashi, Y., Allison, R., Elisei, R., Newbold, K., Licitra, L.F., Sherman, S.I., Ball, D.W., 2015. A phase 2 trial of lenvatinib (E7080) in advanced, progressive, radioiodine-refractory, differentiated thyroid cancer: a clinical outcomes and biomarker assessment. Cancer 121, 2749-2756.

Cai, et al., 2008. Discovery of brivanib alaninate ((S)-((R)-1-(4-(4-fluoro-2-methyl-1H-indol-5-yloxy)-5-methylpyrrolo[2,1 f][1,2,4]triazin-6-yloxy)propan-2-yl)2-aminopropanoate), a novel prodrug of dual vascular endothelial growth factor receptor-2 and fibroblast growth fa. J. Med. Chem.

Capelletti, M., Dodge, M.E., Ercan, D., Hammerman, P.S., Park, S., Kim, J., Sasaki, H., Jablons, D.M., Lipson, D., Young, L., Stephens, P.J., Miller, V.A., Lindeman, N.I., Munir, K.J., Richards, W.G., 2014. Identification of recurrent FGFR3-TACC3 fusion oncogenes from lung adenocarcinoma. Clin. Cancer Res., 6551-6558, http://dx.doi.org/10.1158/1078-0432.CCR-14-1337.

Chang, J., Liu, X., Wang, S., Zhang, Z., Wu, Z., Zhang, X., Li, J., 2014. Prognostic value of FGFR gene amplification in patients with different types of cancer: a systematic review and meta-analysis. PLoS One 9, e105524.

Chell, V., Balmanno, K., Little, A.S., Wilson, M., Andrews, S., Blockley, L., Hampson, M., Gavine, P.R., Cook, S.J., 2013. Tumour cell responses to new fibroblast growth factor receptor tyrosine kinase inhibitors and identification of a 
gatekeeper mutation in FGFR3 as a mechanism of acquired resistance. Oncogene 32, 3059-3070.

Cheng, A.L., Thongprasert, S., Lim, H.Y., Sukeepaisarnjaroen, W., Yang, T.S., WU, C.C., Chao, Y., Chan, S.L., Kudo, M., Ikeda, M., Kang, Y.K., Pan, H., Numata, K., Han, G., Balsara, B., Zhang, Y., Rodriguez, A.M., Zhang, Y., Wang, Y., Poon, R.T., 2016. Randomized, open-label phase 2 study comparing frontline dovitinib versus sorafenib in patients with advanced hepatocellular carcinoma. Heptology 64 (3), 774-784 [Epub 2016 May 17].

Chesi, et al., 2001. Activated fibroblast growth factor receptor 3 is an oncogene that contributes to tumor progression in multiple myeloma. Blood.

Cihoric, N., Savic, S., Schneider, S., Ackermann, I., Bichsel-Naef, M., Schmid, R.A., Lardinois, D., Gugger, M., Bubendorf, L., Zlobec, I., Tapia, C., 2014. Prognostic role of FGFR1 amplification in early-stage non-small cell lung cancer. Br. J. Cancer 110, 2914-2922.

Craddock, et al., 2013. Prognostic value of fibroblast growth factor receptor 1 gene locus amplification in resected lung squamous cell carcinoma. J. Thorac. Oncol

Criscitiello, et al., 2015. Targeting fibroblast growth factor receptor pathway in breast cancer. Curr. Opin. Oncol.

Dhillon, S., 2015. Nintedanib: a review of its use as second-line treatment in adults with advanced non-small cell lung cancer of adenocarcinoma histology. Target. Oncol. 10, 303-310.

Dimitroff, C.J., Klohs, W., Sharma, A., Pera, P., Driscoll, D., Veith, J., Steinkampf, R., Schroeder, M., Klutchko, S., Sumlin, A., Henderson, B., Dougherty, T.J., Bernacki, R.J., 1999. Anti-angiogenic activity of selected receptor tyrosine kinase inhibitors, PD166285 and PD173074: implications for combination treatment with photodynamic therapy. Invest. New Drugs 17, 121-135.

Dransfield, D., Lee, J., Waghorne, C., Bull, C., Savage, R.E., Zhao, X., Yuan, S., Chang, E., Nakuci, E., Eathiraj, S., Cornell-Kennon, S., Gu, X., Ali, S., Chen, C.-R., 2014. Abstract A278: ARQ 087, a multi-tyrosine kinase inhibitor with potent in vitro and in vivo activity in FGFR2 driven models. Mol. Cancer Ther. 12, A278.

Dutt, A., Salvesen, H.B., Chen, T.-H., Ramos, A.H., Onofrio, R.C., Hatton, C., Nicoletti, R., Winckler, W., Grewal, R., Hanna, M., Wyhs, N., Ziaugra, L., Richter, D.J., Trovik, J., Engelsen, I.B., Stefansson, I.M., Fennell, T., Cibulskis, K., Zody, M.C., Akslen, L.A., Gabriel, S., Wong, K.-K., Sellers, W.R., Meyerson, M., Greulich, H., 2008. Drug-sensitive FGFR2 mutations in endometrial carcinoma. Proc. Natl. Acad. Sci. U. S. A. 105, 8713-8717.

Englinger, B., Lotsch, D., Pirker, C., Mohr, T., van Schoonhoven, S., Boidol, B., Lardeau, C.H., Spitzwieser, M., Szabò, P., Heffeter, P., lang, I., Cichna-Markl, M., Grasl-Kraupp, B., Marian, B., Grusch, M., Kubieck, S., Szakacs, G., Berger, W., 2016 Jun 29. Acquired nintedanib resistance in FGFR1-driven small cell lung cancer: role of endothelin-A receptor-activated ABCB1 expression. Oncotarget http://dx.doi.org/10.18632/oncotarget.10324.

Eswarakumar, V.P., Lax, I., Schlessinger, J., 2005. Cellular signaling by fibroblast growth factor receptors. Cytokine Growth Factor Rev. 16, 139-149.

Fauvel, B., Yasri, A., 2014. Antibodies directed against receptor tyrosine kinases: current and future strategies to fight cancer. MAbs 6, 838-851.

French, D.M., Lin, B.C., Wang, M., Adams, C., Shek, T., Hötzel, K., Bolon, B., Ferrando R., Blackmore, C., Schroeder, K., Rodriguez, L.A., Hristopoulos, M., Venook, R., Ashkenazi, A., Desnoyers, L.R., 2012. Targeting FGFR4 inhibits hepatocellular carcinoma in preclinical mouse models. PLoS One 7, e36713, http://dx.doi.org 10.1371/journal.pone.0036713.

Garrido, Pilar, et al., 2015. FP1039/GSK3052230 with chemotherapy in patients with fibroblast growth factor (FGF) pathway deregulated squamous NSCLC or MPM. J. Thorac. Oncol.

Gavine, P.R., Mooney, L., Kilgour, E., Thomas, A.P., Al-Kadhimi, K., Beck, S., Rooney, C., Coleman, T., Baker, D., Mellor, M.J., Brooks, a.N., Klinowska, T., 2012. AZD4547: an orally bioavailable, potent, and selective inhibitor of the fibroblast growth factor receptor tyrosine kinase family. Cancer Res. 72, 2045-2056.

Göke, F., Göke, A., von Mässenhausen, A., Franzen, A., Sharma, R., Kirsten, R., Böhm, D., Kristiansen, G., Stenzinger, A., Wynes, M., Hirsch, F.R., Weichert, W., Heasley, L., Buettner, R., Perner, S., 2013. Fibroblast growth factor receptor 1 as a putative therapy target in colorectal cancer. Digestion 88, 172-181.

Gong, S.-G., 2014. Isoforms of receptors of fibroblast growth factors. J. Cell. Physiol., $1-28$.

Gospodarowicz, D., 1974. Localisation of a fibroblast growth factor and its effect alone and with hydrocortisone on 3T3 cell growth. Nature.

Gotoh, N., 2008. Regulation of growth factor signaling by FRS2 family docking/scaffold adaptor proteins. Cancer Sci. 99, 1319-1325.

Gozgit, J.M., Wong, M.J., Moran, L., Wardwell, S., Mohemmad, Q.K., Narasimhan, N.I., Shakespeare, W.C., Wang, F., Clackson, T., Rivera, V.M., 2012. Ponatinib (AP24534), a multitargeted Pan-FGFR inhibitor with activity in multiple FGFR-amplified or mutated cancer models. Mol. Cancer Ther. 11, 690-699.

Grygielewicz, P., Dymek, B., Bujak, A., Gunerka, P., Stanczak, A., Lamparska-Przybysz, M., Wieczorek, M., Dzwonek, K., Zdzalik, D., 2014. Epithelial-mesenchymal transition confers resistance to selective FGFR inhibitors in SNU-16 gastric cancer cells. Gastric Cancer., http://dx.doi.org/10. 1007/s10120-014-0444-1.

Guagnano, V., Furet, P., Spanka, C., Bordas, V., Le Douget, M., Stamm, C., Brueggen, J., Jensen, M.R., Schnell, C., Schmid, H., Wartmann, M., Berghausen, J., Drueckes, P., Zimmerlin, A., Bussiere, D., Murray, J., Graus Porta, D., 2011. Discovery of 3-(2,6-dichloro-3,5-dimethoxy-phenyl)-1-\{6-[4-(4-ethyl-piperazin-1-yl)phenylamino]-pyrimidin-4-yl\}-1-methyl-urea (NVP-BGJ398), a potent and selective inhibitor of the fibroblast growth factor receptor family of receptor tyrosine kinase. J. Med. Chem. 54, 7066-7083.
Guo, Y., Ding, Y., Zhang, T., An, H., 2016. Sinapine reverses multi-drug resistance in MCF-7/dox cancer cells by downregulating FGFR4/FRS2(-ERK1/2 pathway-mediated NF-кB activation. Phytomedicine 23 (3), 267-273.

Hagel, M., Miduturu, C., Sheets, M., Rubin, N., Weng, W., Stransky, N., Bifulco, N., Kim, J.L., Hodous, B., Brooijmans, N., Shutes, A., Winter, C., Lengauer, C., Kohl, N.E., Guzi, T., 2015. First selective small molecule inhibitor of FGFR4 for the treatment of hepatocellular carcinomas with an activated FGFR4 signaling pathway. Cancer Discov. 5, 424-437.

Hall, T.G., Yu, Y., Eathiraj, S., Wang, Y., Savage, R.E., Lapierre, J.M., Schwartz, B., Abbadessa, G., 2016. 2016 preclinical activity of ARQ 087, a novel inhibitor targeting FGFR dysregulation. PLoS One 11 (9), e0162594.

Harding, M.J., Nechiporuk, a.V., 2012. Fgfr-Ras-MAPK signaling is required for apical constriction via apical positioning of Rho-associated kinase during mechanosensory organ formation. Development 139, 3467

Harding, T.C., Long, L., Palencia, S., Zhang, H., Sadra, A., Hestir, K., Patil, N., Levin, A., Hsu, A.W., Charych, D., Brennan, T., Zanghi, J., Halenbeck, R., Marshall, S.A., Qin, M., Doberstein, S.K., Hollenbaugh, D., Kavanaugh, W.M., Williams, L.T., Baker, K.P., 2013. Blockade of nonhormonal fibroblast growth factors by FP-1039 inhibits growth of multiple types of cancer. Sci. Transl. Med. 5, 178ra39.

Hart, K.C., Robertson, S.C., Kanemitsu, M.Y., Meyer, a.N., Tynan, J.a, Donoghue, D.J., 2000. Transformation and Stat activation by derivatives of FGFR1, FGFR3, and FGFR4. Oncogene 19, 3309-3320.

Haugsten, E.M., Wiedlocha, A., Olsnes, S., Wesche, J., 2010a. Roles of fibroblast growth factor receptors in carcinogenesis. Mol. Cancer Res., 1439-1452.

Haugsten, et al., 2010b. Roles of fibroblast growth factor receptors in carcinogenesis. Mol. Cancer Res.

Heist, et al., 2012. Genetic changes in squamous cell lung cancer: a review. J. Thorac. Oncol. 7, 924-933.

Helsten, T., Elkin, S., Arthur, E., Tomson, B.N., Carter, J., Kurzrock, R., 2015. The Fgfr landscape in cancer: analysis of 4853 tumors by next generation sequencing. Clin. Cancer Res. 4, http://dx.doi.org/10.1158/1078-0432.CCR-14-3212.

Héroult, M., Ocker, M., Kopitz, C., Zopf, D., Hägebarth, A., Ziegelbauer, K., Ince, S., Ellinghaus, P., 2015. Abstract 772: Anti-tumor efficacy of the selective pan-FGFR inhibitor BAY 1163877 in preclinical squamous cell carcinoma models of different origin. Cancer Res. 75, 772.

Heroult, et al., 2014. Abstract 1739: preclinical profile of BAY 1163877 - a selective pan-FGFR inhibitor in phase 1 clinical trial. Cancer Res.

Herrera-Abreu, M.T., Pearson, A., Campbell, J., Shnyder, S.D., Knowles, M.A., Ashworth, A., Turner, N.C., 2013 Sep. Parallel RNA interference screens identify EGFR activation as an escape mechanism in FGFR3-mutant cancer. Cancer Discov. 3 (9), 1058-1071.

Hibi, et al., 2016. FGFR gene alterations in lung squamous cell carcinoma are potential targets for the multikinase inhibitor nintedanib. Cancer Sci. 107, http://dx.doi.org/10.1111/cas.13071.

Hong, D.S., Henary, H., Falchook, G.S., Naing, A., Fu, S., Moulder, S., Wheler, J.J., Tsimberidou, A., Durand, J.B., Khan, R., Yang, P., Johansen, M., Newman, R.A., Kurzrock, R., 2014. First-in-human study of pbi-05204, an oleander-derived inhibitor of akt, fgf-2, nf-кB and p70s6k, in patients with advanced solid tumors. Invest. New Drugs 32, 1204-1212, http://dx.doi.org/10.1007/s10637014-0127-0.

Inokuchi, M., Fujimori, Y., Otsuki, S., Sato, Y., Nakagawa, M., Kojima, K., 2015. Therapeutic targeting of fibroblast growth factor receptors in gastric cancer. Gastroenterol. Res. Pract. 2015, 796380, http://dx.doi.org/10.1155/2015/ 796380.

Johnson, D.E., Williams, L.T., 1992. Structural and Functional Diversity in the FGf Receptor Multigene Family. Adv. Cancer Res. 60, 1-41, http://dx.doi.org/10. 1016/S0065-230X(08)60821-0.

Kim, et al., 2016a. Fibroblast growth factor receptor 1 gene amplification is associated with poor survival and cigarette smoking dosage in patients with resected squamous cell lung cancer. JCO 31, 731-737.

Kim, S.M., Kim, H., Yun, M.R., Kang, H.N., Pyo, K.H., Park, H.J., Lee, J.M., Choi, H.M., Ellinghaus, P., Ocker, M., Paik, S., Kim 5., H.R., 2016b. Activation of the Met kinase confers acquired drug resistance in FGFR-targeted lung cancer therapy. Cho BC Oncogenesis 5 (7), e241.

Konecny, G.E., Finkler, N., Garcia, A.A., Lorusso, D., Lee, P.S., Rocconi, R.P., Fong, P.C., Squires, M., Mishra, K., Upalawanna, A., Wang, Y., Kristeleit, R., 2015. Second-line dovitinib (TKI258) in patients with FGFR2-mutated or FGFR2-non-mutated advanced or metastatic endometrial cancer: a non-randomised, open-label, two-group, two-stage, phase 2 study. Lancet. Oncol. 16, 686-694.

Konecny, G.E., Kolarova, T., O’Brien, N.A., Winterhoff, B., Yang, G., Qi, J., Qi, Z., Venkatesan, N., Ayala, R., Luo, T., Finn, R.S., Kristof, J., Galderisi, C., Porta, D.G., Anderson, L., Shi, M.M., Yovine, A., Slamon, D.J., 2013. Activity of the fibroblast growth factor receptor inhibitors dovitinib (TKI258) and NVP-BGJ398 in human endometrial cancer cells. Mol. Cancer Ther. 12, 632-642.

Koole, et al., 2016. FGFR1 is a potential prognostic biomarker and therapeutic target in head and neck squamous cell carcinoma. Clin. Cancer Res.

Kwak, Y., Cho, H., Hur, W., Sim, T., 2015. Antitumor effects and mechanisms of azd4547 on fgfr2-deregulated endometrial cancer cells. Mol. Cancer Ther. 14, 2292-2302.

Kyriakos, et al., 2015. Phase 1, first-in-human study of ARQ 087, an oral pan-Fibroblast Growth Factor Receptor (FGFR) inhibitor, in patients (pts) with advanced solid tumors. ASCO Annu. Meet.

Lecia, et al., 2014. Abstract CT326: Phase I study of BGJ398, a selective pan-FGFR inhibitor in genetically preselected advanced solid tumors. AACR Annu. Meet. 
Lee, C.-K., Lee, M.E., Lee, W.S., Kim, J.M., Park, K.H., Kim, T.S., Lee, K.Y., Ahn, J.B., Chung, H.C., Rha, S.Y., 2015. Dovitinib (TKI258), a multi-target angiokinase inhibitor, is effective regardless of KRAS or BRAF mutation status in colorectal cancer. Am. J. Cancer Res. 5, 72-86.

Lehnen, N.C., von Mässenhausen, A., Kalthoff, H., Zhou, H., Glowka, T., Schütte, U., Höller, T., Riesner, K., Boehm, D., Merkelbach-Bruse, S., Kirfel, J., Perner, S., Gütgemann, I., 2013. Fibroblast growth factor receptor 1 gene amplification in pancreatic ductal adenocarcinoma. Histopathology 63, 157-166.

Lew, et al., 2009. The precise sequence of FGF receptor autophosphorylation is kinetically driven and is disrupted by oncogenic mutations. Sci. Signal. 2, ra6.

Lim, et al., 2016a. Efficacy and safety of dovitinib in pretreated patients with advanced squamous non-small cell lung cancer with FGFR1 amplification: A single-arm, phase 2 study. Cancer.

Lim, S.M., Kim, H.R., Cho, E.K., Min, Y.J., Ahn, M.J., Park, K., Cho, B.C., Lee, J.H., Jeong, H.C., Kim, E.K., Kim, J.H., 2016 Jun 14. Targeted sequencing identifies genetic alterations that confer primary resistance to EGFR tyrosine kinase inhibitor (Korean Lung Cancer Consortium). Oncotarget 7 (24), 36311-36320.

Lu, et al., 2008a. Genetic mosaic analysis reveals FGF receptor 2 function in terminal end buds during mammary gland branching morphogenesis. Dev. Biol. 321, 77-87.

Lu, et al., 2008b. Fibroblast growth factors, their receptors and signaling. Dev. Biol. 7, 165-197.

Lu, et al., 2008c. An Open-label, Multicenter, Phase II Study of Dovitinib in Advanced Thyroid Cancer - Full Text View - ClinicalTrials.gov. Dev. Biol.

Lu, et al., 2008d. FGFR2 gene amplification in gastric cancer predicts sensitivity to the selective FGFR inhibitor AZD4547. Dev. Biol. 19, 2572-2583.

Lu, et al., 2008e. The inhibitory anti-FGFR3 antibody, PRO-001, is cytotoxic to t(4;14) multiple myeloma cells. Dev. Biol. 107, 4039-4046.

Marshall, M.E., Hinz, T.K., Kono, S.A., Singleton, K.R., Bichon, B., Ware, K.E., Marek, L., Frederick, B.A., Raben, D., Heasley, L.E., 2011. Fibroblast growth factor receptors are components of autocrine signaling networks in head and neck squamous cell carcinoma cells. Clin. Cancer Res. 17, 5016-5025.

Matulonis, U.A., Lee, J., Lasonde, B., Tew, W.P., Yehwalashet, A., Matei, D., Behbakht, K., Grothusen, J., Fleming, G., Lee, N.K., Arnott, J., Bray, M.R., Fletcher, G., Brokx, R.D., Castonguay, V., Mackay, H., Sidor, C.F., Oza, A.M., 2013. ENMD-2076, an oral inhibitor of angiogenic and proliferation kinases, has activity in recurrent, platinum resistant ovarian cancer. Eur. J. Cancer 49, 121-131.

Milowsky, M.I., Dittrich, C., Durán, I., Jagdev, S., Millard, F.E., Sweeney, C.J., Bajorin, D., Cerbone, L., Quinn, D.I., Stadler, W.M., Rosenberg, J.E., Lochheed, M., Sen, P., Squires, M., Shi, M., Sternberg, C.N., 2014. Phase 2 trial of dovitinib in patients with progressive FGFR3-mutated or FGFR3 wild-type advanced urothelial carcinoma. Eur. J. Cancer 50, 3145-3152.

Mizumaki, T., Togashi, Y., Naruki, S., Banno, E., Terashima, M., De Velasco, M.A., Sakai, K., Yoneshige, A., Hayashi, H., Tomida, S., Nakajima, T.E., Fujino, T., Boku, N., Ito, A., Nakagawa, K., Nishio, K., 2016 Feb 24. Significance of FGF9 gene in resistance to anti-EGFR therapies targeting colorectal cancer: A subset of colorectal cancer patients with FGF9 upregulation may be resistant to anti-EGFR therapies. Mol. Carcinog., http://dx.doi.org/10.1002/mc.22476.

Monaco, et al., 2016. FGFR1 Amplification in Squamous Cell Carcinoma of theFujita Y Lung with Correlation of Primary and Metastatic Tumor Status. Am J Clin Oncol.

Murakami, et al., 2009. Fibroblast growth factor regulation of neovascularization. Curr. Opin. Hematol. 15, 215-220.

Myung-Ju, et al., 2016. Efficacy and safety of dovitinib in pretreated advanced squamous non-small cell lung cancer with FGFR1 amplification: a single-arm, phase II study. J. Thorac. Oncol.

Nakanishi, Y., Akiyama, N., Tsukaguchi, T., Fujii, T., Sakata, K., Sase, H., Isobe, T., Morikami, K., Shindoh, H., Mio, T., Ebiike, H., Taka, N., Aoki, Y., Ishii, N., 2014. The fibroblast growth factor receptor genetic status as a potential predictor of the sensitivity to CH5183284/Debio 1347, a novel selective FGFR inhibitor. Mol. Cancer Ther. 13, 2547-2558.

Nelson, et al., 2016. Oncogenic gene fusion FGFR3-TACC3 is regulated by tyrosine phosphorylation. Mol. Cancer Res.

Nogova, L., Sequist, L.V., Perez Garcia, J.M., Andre, F., Delord, J.P., Hindalgo, M. Schellens, J.H., Cassier, P.A., Camidge, D.R., Schuler, M., Vaishampayan, U., Burris, H., Tian, G.G., Campone, M., Wainberg, Z.A., Lim, W.T., LoRusso, P., Shapiro, G., Parker, K., Chen, X., Choudhry, S., Ringeisen, F., Graus-Porta, D., Porter, D., Isaacs, R., Buettner, R., Wolf, J., Wolf, J., 2016. Evaluation of BGJ398, a fibroblast growth factor receptor 1-3 kinase inhibitor, in patients with advanced solid tumors harboring genetic alterations in fibroblast growth factor receptors: results of a global Phase I, Dose-Escalation and Dose-Expansion Study. J. Clin. Oncol., 2016 Nov 21: JCO2016672048.

Ochiiwa, H., Fujita, H., Itoh, K., Sootome, H., Hashimoto, A., Fujioka, Y., Nakatsuru, Y., Oda, N., Yonekura, K., Hirai, H., Utsugi, T., 2014. Abstract A270: TAS-120, a highly potent and selective irreversible FGFR inhibitor, is effective in tumors harboring various FGFR gene abnormalities. Mol. Cancer Ther. 12, A270, http:// dx.doi.org/10.1158/1535-7163.TARG-13-A270.

ODonnell, et al., 2012. A Phase I Dose-escalation Study of MFGR1877S, a human monoclonal anti-fibroblast growth factor receptor 3 (FGFR3) antibody, in patients (pts) with advanced solid tumors. Eur. J. Cancer.

Ohta, M., Kawabata, T., Yamamoto, M., Tanaka, T., Kikuchi, H., Hiramatsu, Y., Kamiya, K., Baba, M., Konno, H., 2009. TSU68, an antiangiogenic receptor tyrosine kinase inhibitor, induces tumor vascular normalization in a human cancer xenograft nude mouse model. Surg. Today 39, 1046-1053.

Ornitz, D.M., Itoh, N., 2015. The fibroblast growth factor signaling pathway. Wiley Interdiscip. Rev. Dev. Biol. 4, 215-266.
Pai, R., Dunlap, D., Qing, J., Mohtashemi, I., Hotzel, K., French, D.M., 2008. Inhibition of fibroblast growth factor 19 reduces tumor growth by modulating beta-catenin signaling. Cancer Res. 68, 5086-5095.

Pandith, et al., 2008. Oncogenic role of fibroblast growth factor receptor 3 in tumorigenesis of urinary bladder cancer. Dev. Biol. 31, 398-406.

Parker, B.C., Engels, M., Annala, M., Zhang, W., 2014. Emergence of FGFR family gene fusions as therapeutic targets in a wide spectrum of solid tumours. J. Pathol. 232, 4-15.

Patani, H., Bunney, T.D., Thiyagarajan, N., Norman, R.A., Ogg, D., Breed, J., Ashford, P., Potterton, A., Edwards, M., Williams, S.V., Thomson, G.S., Pang, C.S., Knowles, M.A., Breeze, A.L., Orengo, C., Phillips, C., Katan, M., 2016 Apr 26. Landscape of activating cancer mutations in FGFR kinases and their differential responses to inhibitors in clinical use. Oncotarget 7 (17), 24252-24268.

Peng, W.C., Lin, X., Torres, J., 2009. The strong dimerization of the transmembrane domain of Williams SV the fibroblast growth factor receptor (FGFR) is modulated by C-terminal juxtamembrane residues. Protein Sci. 18, 450-459.

Porta, C., Giglione, P., Liguigli, W., Paglino, C., 2015. Dovitinib (CHIR258, TKI258): structure, development and preclinical and clinical activity. Future Oncol. 11, 39-50.

Powers, et al., 2000. Fibroblast growth factors, their receptors and signaling., pp. 165-197.

Prince, H.M., Hönemann, D., Spencer, A., Rizzieri, D.A., Stadtmauer, E.A., Roberts, A.W., Bahlis, N., Tricot, G., Bell, B., Demarini, D.J., Benjamin Suttle, A., Baker, K.L., Pandite, L.N., 2009. Vascular endothelial growth factor inhibition is not an effective therapeutic strategy for relapsed or refractory multiple myeloma: a phase 2 study of pazopanib (GW786034). Blood 113, 4819-4820.

Reck, M., Kaiser, R., Mellemgaard, A., Douillard, J.-Y., Orlov, S., Krzakowski, M., von Pawel, J., Gottfried, M., Bondarenko, I., Liao, M., Gann, C.-N., Barrueco, J., Gaschler-Markefski, B., Novello, S., 2014. Docetaxel plus nintedanib versus docetaxel plus placebo in patients with previously treated non-small-cell lung cancer (LUME-Lung 1): a phase 3, double-blind, randomised controlled trial. Lancet Oncol. 15, 143-155.

Repana, et al., 2015. Targeting FGF19/FGFR4 pathway: a novel therapeutic strategy for hepatocellular carcinoma. Diseases.

Rooney, C., Geh, C., Williams, V., Heuckmann, J.M., Menon, R., Schneider, P., Al-kadhimi, K., Dymond, M., Smith, R., Baker, D., French, T., Smith, P.D., Harrington, E.A., Barrett, C., Kilgour, E., 2016. Characterization of FGFR1 locus in sqNSCLC reveals a broad and heterogeneous amplicon. PLoS One 1-18, http://dx.doi.org/10.1371/journal.pone.0149628.

Schäfer, N., 2016. Phase I trial of dovitinib (TKI258) in recurrent glioblastoma. J Cancer Res. Clin. Oncol.

Scheid, C., Reece, D., Beksac, M., Spencer, A., Callander, N., Sonneveld, P., Kalimi, G., Cai, C., Shi, M., Scott, J.W., Stewart, A.K., 2015. Phase 2 study of dovitinib in patients with relapsed or refractory multiple myeloma with or without $\mathrm{t}(4 ; 14)$ translocation. Eur. J. Haematol. 95, 316-324.

Schmidt, et al., 2015. Targeting fibroblast growth factor receptor (FGFR) with BGJ398 in a gastric cancer model. Anticancer Res.

Sleeman, M., Fraser, J., McDonald, M., Yuan, S., White, D., Grandison, P., Kumble, K. Watson, J.D., Murison, J.G., 2001. Identification of a new fibroblast growth factor receptor, FGFR5. Gene 271, 171-182.

Smyth, et al., 2015. Phase II multicenter proof of concept study of AZD4547 in FGFR amplified tumours. ASCO Annu. Meet.

Sohl, C.D., Ryan, M.R., Luo, B., Frey, K.M., Anderson, K.S., 2015. Illuminating the molecular mechanisms of tyrosine kinase inhibitor resistance for the FGFR1 gatekeeper mutation: the Achilles' heel of targeted therapy. ACS Chem. Biol.

Sonpavde, et al., 2009. Pazopanib for the treatment of renal cell carcinoma and other malignancies. Drugs Today.

Soria, J.-C., DeBraud, F., Bahleda, R., Adamo, B., Andre, F., Dienstmann, R., Dientsmann, R., Delmonte, A., Cereda, R., Isaacson, J., Litten, J., Allen, A., Dubois, F., Saba, C., Robert, R., D'Incalci, M., Zucchetti, M., Camboni, M.G., Tabernero, J., 2014. Phase I/IIa study evaluating the safety, efficacy, pharmacokinetics, and pharmacodynamics of lucitanib in advanced solid tumors. Ann. Oncol. 25, 2244-2251

Su, X., Zhan, P., Gavine, P.R., Morgan, S., Womack, C., Ni, X., Shen, D., Bang, Y.-J., Im, S.-A., Ho Kim, W., Jung, E.-J., Grabsch, H.I., Kilgour, E., 2014. FGFR2 amplification has prognostic significance in gastric cancer: results from a large international multicentre study. Br. J. Cancer 110, 967-975.

Sun, X., Guo, W., Shen, J.K., Mankin, H.J., Hornicek, F.J., Duan, Z., 2015. Rhabdomyosarcoma: advances in molecular and cellular biology. Sarcoma 2015, 232010.

Tabernero, J., Bahleda, R., Dienstmann, R., Infante, J.R., Mita, A., Italiano, A., Calvo, E., Moreno, V., Adamo, B., Gazzah, A., Zhong, B., Platero, S.J., Smit, J.W., Stuyckens, K., Chatterjee-Kishore, M., Rodon, J., Peddareddigari, V., Luo, F.R., Soria, J.-C., 2015. Phase I dose-escalation study of JNJ-42756493, an oral pan-fibroblast growth factor receptor inhibitor, in patients with advanced solid tumors. J. Clin. Oncol 33, 3401-3408.

Tolcher, et al., 2016. A phase I, first in human study of FP-1039 (GSK3052230), a novel FGF ligand trap, in patients with advanced solid tumors. Ann Oncol.

Verstraete, et al., 2015. In vitro and in vivo evaluation of the radiosensitizing effect of a selective FGFR inhibitor (JNJ-42756493) for rectal cancer. BMC Cancer.

Wan, et al., 2014. Prostate cancer cell-stromal cell crosstalk via FGFR1 mediates antitumor activity of dovitinib in bone metastases. Sci. Transl. Med.

Wang, J., Mikse, O., Liao, R.G., Li, Y., Tan, L., Janne, P.A., Gray, N.S., Wong, K., Hammerman, P.S., 2015. Ligand-associated ERBB2/3 activation confers acquired resistance to FGFR inhibition in FGFR3-dependent cancer cells. Oncogene 34, 2167-2177. 
Yu Wang, Xiwei Ding, Shaoqing Wang, Moser, C.D., Shaleh, H.M., Mohamed, E.A Roongruedee Chaiteerakij, Allotey, L.K., Gang Chen, Katsuyuki Miyabe, McNulty, M.S., Albert Ndzengue, Barr Fritcher, E.G., Knudson, R.A., Greipp, P.T., Clark, K.J., Torbenson, M.S., Kipp, B.R., Jie Zhou, Barrett, M.T., Gustafson, M.P., Alberts, S.R., Borad, M.J., Roberts, L.R., 2016. * 2016 Antitumor effect of FGFR inhibitors on a novel cholangiocarcinoma patient derived xenograft mouse model endogenously expressing an FGFR2-CCDC6 fusion protein. Cancer Lett. 380 (1), 163-173.

Wang, L., Park, H., Chhim, S., Ding, Y., Jiang, W., Queen, C., Kim, K.J., 2012. A novel monoclonal antibody to fibroblast growth factor 2 effectively inhibits growth of hepatocellular carcinoma xenografts. Mol. Cancer Ther. 11, 864-872.

Ware, K.E., Marshall, M.E., Heasley, L.R., Marek, L., Hinz, T.K., Hercule, P., Helfrinch, B.A., Doebele, R.C., Heasley, L.E., 2010 Nov 29. Rapidly acquired resistance to EGFR tyrosine kinase inhibitors in NSCLC cell lines through de-repression of FGFR2 and FGFR3 expression. PLoS One 5 (11), e14117.

Ware, K.E., Hinz, T.K., Kleczko, E., Singleton, K.R., Marek, L.A., Helfrinch, B.A., Cummings, C.T., Graham, D.K., Astlinf, D., Tan, A.C., Heasley, L.E., 2013 Mar 25. A mechanism of resistance to gefitinib mediated by cellular reprogramming and the acquisition of an FGF2-FGFR1 autocrine growth loop. Oncogenesis 2, e39.

Wedge, S.R., Kendrew, J., Hennequin, L.F., Valentine, P.J., Barry, S.T., Brave, S.R., Smith, N.R., James, N.H., Dukes, M., Curwen, J.O., Chester, R., Jackson, J.A Boffey, S.J., Kilburn, L.L., Barnett, S., Richmond, G.H.P., Wadsworth, P.F., Walker, M., Bigley, A.L., Taylor, S.T., Cooper, L., Beck, S., Jürgensmeier, J.M., Ogilvie, D.J., 2005. AZD2171: a highly potent, orally bioavailable, vascular endothelial growth factor receptor-2 tyrosine kinase inhibitor for the treatment of cancer. Cancer Res. 65, 4389-4400.

Welti, J.C., Gourlaouen, M., Powles, T., Kudahetti, S.C., Wilson, P., Berney, D.M. Reynolds, A.R., 2011. Fibroblast growth factor 2 regulates endothelial cell sensitivity to sunitinib. Oncogene 30,1183-1193.

Wilhelm, et al., 2011. Regorafenib (BAY 73-4506): a new oral multikinase inhibitor of angiogenic, stromal and oncogenic receptor tyrosine kinases with potent preclinical antitumor activity. Int. J. Cancer.

Wu, Y.-M., Su, F., Kalyana-Sundaram, S., Khazanov, N., Ateeq, B., Cao, X., Lonigro, R.J., Vats, P., Wang, R., Lin, S.-F., Cheng, A.-J., Kunju, L.P., Siddiqui, J., Tomlins, S.A., Wyngaard, P., Sadis, S., Roychowdhury, S., Hussain, M.H., Feng, F.Y.,
Zalupski, M.M., Talpaz, M., Pienta, K.J., Rhodes, D.R., Robinson, D.R., Chinnaiyan, A.M., 2013. Identification of targetable FGFR gene fusions in diverse cancers. Cancer Discov. 3, 636-647.

Yamamoto, Y., Matsui, J., Matsushima, T., Obaishi, H., Miyazaki, K., Nakamura, K., Tohyama, O., Semba, T., Yamaguchi, A., Hoshi, S.S., Mimura, F., Haneda, T., Fukuda, Y., Kamata, J.-I., Takahashi, K., Matsukura, M., Wakabayashi, T., Asada, M., Nomoto, K.-I., Watanabe, T., Dezso, Z., Yoshimatsu, K., Funahashi, Y. Tsuruoka, A., 2014. Lenvatinib, an angiogenesis inhibitor targeting VEGFR/FGFR, shows broad antitumor activity in human tumor xenograft models associated with microvessel density and pericyte coverage. Vasc. Cell 6,18 .

Yang, Chen, H., Zeng, L., Ai, J., Geng, M., Hu, Y., et al., 2017. Discovery of novel Ponatinib analogues for reducing KDR activity as potent FGFRs inhibitors. Eur. J. Med. Chem. 126, 122-132.

Yao, T.-J., Zhu, J.-H., Peng, D.-F., Cui, Z., Zhang, C., Lu, P., 2015. AZD-4547 exerts potent cytostatic and cytotoxic activities against fibroblast growth factor receptor (FGFR)-expressing colorectal cancer cells. Tumour Biol. 36, 5641-5648.

Zhang, J., Zhang, L., Su, X., Li, M., Xie, L., Malchers, F., Fan, S., Yin, X., Xu, Y., Liu, K., Dong, Z., Zhu, G., Qian, Z., Tang, L., Schöttle, J., Zhan, P., Ji, Q., Kilgour, E., Smith, P.D., Brooks, A.N., Thomas, R.K., Gavine, P.R., 2012. Translating the therapeutic potential of AZD4547 in FGFR1-amplified non-small cell lung cancer through the use of patient-derived tumor xenograft models. Clin. Cancer Res. 18, 6658-6667.

Zhao, G., Li, W.-Y., Chen, D., Henry, J.R., Li, H.-Y., Chen, Z., Zia-Ebrahimi, M., Bloem, L., Zhai, Y., Huss, K., Peng, S.-B., McCann, D.J., 2011. A novel, selective inhibitor of fibroblast growth factor receptors that shows a potent broad spectrum of antitumor activity in several tumor xenograft models. Mol. Cancer Ther. 10, $2200-2210$

Zhao, et al., 2010. Monoclonal antibodies to fibroblast growth factor receptor 2 effectively inhibit growth of gastric tumor xenografts. Clin. Cancer Res.

Zhou, et al., 2011. Structural mechanism of the Pan-BCR-ABL inhibitor ponatinib (AP24534): lessons for overcoming kinase inhibitor resistance. Chem. Biol. Drug Des. 